NBER WORKING PAPER SERIES

\title{
URBAN MOBILITY AND THE EXPERIENCED ISOLATION \\ OF STUDENTS AND ADULTS
}

\author{
Cody Cook \\ Lindsey Currier \\ Edward L. Glaeser \\ Working Paper 29645 \\ http://www.nber.org/papers/w29645 \\ NATIONAL BUREAU OF ECONOMIC RESEARCH \\ 1050 Massachusetts Avenue \\ Cambridge, MA 02138 \\ January 2022
}

This project was reviewed and approved by the Stanford Institutional Review Board (protocol IRB-62185). Glaeser acknowledges support from the Star Family Challenge for Promising Scientific Research. We thank Allison Arieff, Kiran Jain, and Alexei Pozdnoukhov at Replica for facilitating access to the data. The views expressed herein are those of the authors and do not necessarily reflect the views of the National Bureau of Economic Research.

At least one co-author has disclosed additional relationships of potential relevance for this research. Further information is available online at http://www.nber.org/papers/w29645.ack

NBER working papers are circulated for discussion and comment purposes. They have not been peer-reviewed or been subject to the review by the NBER Board of Directors that accompanies official NBER publications.

(C) 2022 by Cody Cook, Lindsey Currier, and Edward L. Glaeser. All rights reserved. Short sections of text, not to exceed two paragraphs, may be quoted without explicit permission provided that full credit, including $(\odot$ notice, is given to the source. 
Urban Mobility and the Experienced Isolation of Students and Adults

Cody Cook, Lindsey Currier, and Edward L. Glaeser

NBER Working Paper No. 29645

January 2022

JEL No. C55,I30,J13,R30

\begin{abstract}
$\underline{\text { ABSTRACT }}$
Do urban children live more segregated lives than urban adults? Using cellphone location data and following the 'experienced isolation' methodology of Athey et al. (2021), we compare the isolation of students over the age of 16-who we identify based on their time spent at a high school-and adults. We find that students in cities experience significantly less integration in their day-to-day lives than adults. The average student experiences $27 \%$ more isolation outside of the home than the average adult. Even when comparing students and adults living in the same neighborhood, exposure to devices associated with a different race is $20 \%$ lower for students. Looking at more broad measures of urban mobility, we find that students spend more time at home, more time closer to home when they do leave the house, and less time at school than adults spend at work. Finally, we find correlational evidence that neighborhoods with more geographic mobility today also had more intergenerational income mobility in the past. We hope future work will more rigorously test the hypothesis that different geographic mobility patterns for children and adults can explain why urban density appears to boost adult wages but reduce intergenerational income mobility.
\end{abstract}

Cody Cook

Graduate School of Business

Stanford University

codycook@stanford.edu

Lindsey Currier

Harvard University

lindseyacurrier@gmail.com
Edward L. Glaeser

Department of Economics

315A Littauer Center

Harvard University

Cambridge, MA 02138

and NBER

eglaeser@harvard.edu 


\section{Introduction}

Are the lives of urban children more segregated than the lives of urban adults? Athey et al. (2021) find that even where residential segregation is high, white and non-white residents interact during the day as they move around their city. ${ }^{1}$ Yet while restaurants, shops, and offices have become less segregated since the 1960s, big city schools have not (Orfield et al., 1994). An adult living in a segregated neighborhood may go to a workplace filled with heterogeneous individuals, but her child may go to a segregated school and return home to play with the children next door.

The experienced isolation of the young is particularly important because segregation appears to harm upward mobility (Cutler and Glaeser, 1997; Chetty and Hendren, 2018). The Opportunity Atlas data (Chetty et al., 2018) documents a robust negative correlation between urban density and adult earnings for the children of poor parents - children who grew up in the densest Census tracts end up about five percentiles lower in the adult income distribution than children from moderately dense Census tracts (Glaeser and Tan, 2021). This fact is all the more surprising because wage growth for adults appears to be faster in larger cities (Glaeser and Mare, 2001; Roca and Puga, 2017). One possible explanation for why cities appear to increase human capital accumulation for adults, but not for children, is that students live more isolated lives than adults.

In this paper, we test whether the same metropolis that connects grown-ups also isolates children. We follow the methodology of Athey et al. (2021), who use cell phone GPS data to measure the racial isolation individual experience each day by looking at the mobility of people who live in majority white and majority non-white neighborhoods. We use a similar sample of GPS-enabled devices to examine the diversity of interactions of adults and students in the 100 most populous metropolitan areas in the US. Using these data, we also directly measure other indicators of urban mobility, such as time in at school or work, time at home, time spent in neighborhoods with highly educated residents, and the exploration of new places.

Our data consists of the location histories for a national longitudinal sample of GPS-enabled devices in 2019. For each device, we infer whether it likely belongs to a student or adult by whether

\footnotetext{
${ }^{1}$ The 'experienced isolation' measure in Athey et al. (2021) builds on the 'activity space' literature in sociology, surveyed in Cagney et al. (2020)
} 
it has a regular presence in a high school during weekdays. For privacy reasons, the data exclude anyone under the age of 16 , so our focus is on students aged 16-18. Our school-identified group will also include teachers and other school personnel, which will lead the measured differences between adults and students to be muted since our 'student' sample also contains adults.

Having identified probable students, we first replicate the 'experienced isolation' populationlevel measure defined by Athey et al. (2021) for adults and students separately. Like Athey et al. (2021), we do not have data on race, but follow their methodology by looking at devices from neighborhoods with differing racial compositions. We label a 'white device' (WD) as one that lives in a Census block group that is majority white (non-Hispanic) and a 'non-white device' (NWD) as one that lives in a majority non-white block group. Our estimates are therefore an examination of how much individuals from predominantly non-white neighborhoods interact with individuals from predominantly white neighborhoods.

Overall, we estimate experienced isolation to be 0.65 for adults and 0.73 for students, which implies that the average student WD is exposed to 73 percentage points more WDs than the average student NWD. If we exclude time at home, isolation for both groups declines and the gap between the students and adults becomes proportionally larger. Experienced isolation excluding time at home is 0.29 for adults and 0.37 for children, making students $27 \%$ more isolated outside the house than adults.

To unpack these figures, we move from these overall segregation estimates to a more detailed look at patterns by race, age, and location. We first look at exposure to diversity, which we define at the device level as the average percent of time spent near devices from neighborhoods of a predominantly different race. The average exposure to diversity is only 0.125 , and it is about $30 \%$ lower for students than for adults. Aggregate exposure to diversity is lower for NWDs than WDs, but, even when comparing students from the same tract, exposure to diversity is lower for students than adults for both WDs and NWDs.

Looking at more general measures of urban mobility, we find clear ways in which students live more isolated lives. Students spend more at home and in their neighborhood and spend less time at school than adults spend at work. When they do leave the house, students stay closer to home and 
spend fewer days traveling outside of their home city. Students go to fewer restaurants and shops, with more visits to parks and entertainment places instead. On the other hand, students visit more unique locations in the city, suggesting their less routinized lives lead to more exploration. Students also generally spend their time in more prosperous and better educated areas, even relative to adults who live in the same neighborhood.

To examine whether our results are the same at the fringes of a city and its center, we turn to the connection between population density and outcomes. Density is both a defining characteristic of urbanism and is negatively associated with children's outcomes in the Opportunity Atlas data (Chetty and Hendren, 2018; Glaeser and Tan, 2021). Adults' time at home declines with density while students' time at home increases with density. Meanwhile, time at work is increasing in density for adults but decreasing in density for students. We also find that in low density locales, students explore more unique locations than adults, while in high density locales, this pattern is reversed and adults explore more unique locations. Finally, we see that, while students generally spend more of their time than adults in areas with high levels of human capital, this pattern is reversed in the highest density neighborhoods. Taken together, these results suggest that while density enables the employment and exposure of adults to more skilled people, density reduces the time at school for students and their interactions with other educated people.

Finally, we examine the correlation between place-based measures of income mobility from Chetty and Hendren (2018) and several mobility patterns from our data. Although our cellphone data is modern while mobility data refers to a cohort born between 1978 and 1983, there are some clear correlations. Most notably, Census tracts where residents have more exposure to diversity, spend more time outside of the city, and visit more unique locations within the city tend to have higher upward income mobility. 


\section{Data \& Measuring Experienced Isolation}

\subsection{GPS Mobility Data}

Our primary data come from a sample of GPS enabled devices for all of 2019. Access to the data is provided by Replica, an urban data platform. For each device, we observe a unique device identifier and a sequence of 'stays' at different locations. ${ }^{2}$ Each stay includes the geographic coordinates, entry time, and exit time. We have no direct information about the device's user, and consequently must infer whether a device is a student and their likely race from the location histories of the device. We provided additional details on the data construction in Appendix A.

\subsection{Identifying Likely Student and Adult Devices}

For each device-quarter in the data, we identify 'home' as a device's most common overnight location and work as a device's most common daytime non-home location. ${ }^{3}$ To focus on urban environments, we look only at devices living within the 100 most populous metropolitan CoreBased Statistical Areas (CBSAs). The smallest CBSA to make the cut is the Spokane-Spokane Valley Area in Washington. The resulting sample includes 12.1 million unique devices with home and work detected, or 19.3 million device-quarters.

To label a device as a student, we match 'work' locations to school parcels. We identify the locations of high schools using data from the National Center for Education Statistics (NCES), which is described in Appendix Section A.2. We include only high schools, as our GPS data is meant to exclude individuals under 16 years old. We identify 391,866 devices that are likely high school students at these schools. Appendix Figure A.1 shows that our counts of students at a school are highly correlated with the enrollment reported in the NCES.

Our method of identifying students will also capture teachers and staff. This will add noise and, to the extent adults working at schools are similar to other adults, will bias our measures towards

\footnotetext{
${ }^{2}$ This data is similar in nature to the data used by Athey et al. (2021); however, rather than observing individual pings each time a device connects to GPS, we observe only these aggregate stays. A consequence of this aggregation is that our data do not include time in transit.

${ }^{3}$ We exclude all devices for which we cannot identify a work location. The majority of these devices have insufficient coverage in the data to confidently identify a work location, but others are either unemployed or employed in occupations without a static work location, such as mailmen or taxi drivers.
} 
finding no differences between students and adults. However, there does appear to be signal in the classification - for example, when examining the types of establishments they visit, we find that 'students' go to far fewer bars and beer/liquor stores than adults.

\subsection{Inferring Device 'Race'}

Following Athey et al. (2021), we classify devices as either a 'white device' (WD) or 'non-white device' (NWD) based on whether or not their home block group is majority white alone (nonHispanic) in the American Community Survey (ACS). ${ }^{4}$ The average home block group for WD is $78.5 \%$ white, while the average home block group for NWD is $21.0 \%$ white. These assigned races are likely to overestimate true experienced isolation, since the interactions of the minority group of a block will be identified with the majority. However, as long as this misattribution is the same for adults and students, our analysis of differences between these two groups will not be biased.

\subsection{Measuring Experienced Isolation and Diversity}

We follow Athey et al. (2021) as closely as possible to estimate experienced isolation, but some modifications are required because our data are at the aggregate 'stay' level rather than 'ping' level. ${ }^{5}$ Aggregate experienced isolation — setting aside adult vs. student types for now - is defined as

$$
\mathrm{EI}_{a}=\frac{1}{\left|\mathrm{WD}_{a}\right|} \sum_{i \in \mathrm{WD}_{a}} \int_{t=0}^{1} s(l(i, t), t) d t-\frac{1}{\left|\mathrm{NWD}_{a}\right|} \sum_{i \in \mathrm{NWD}_{a}} \int_{t=0}^{1} s(l(i, t), t) d t
$$

where $a$ is a given CBSA, $\mathrm{WD}_{a}$ is the set of of white devices, $\mathrm{NWD}_{a}$ is the set of non-white devices, and $s(l(i, t), t)$ is the share of individuals in $i$ 's location $l$ at time $t$ who are from group $W D$. In words, this is simply the difference between the average exposure of WDs to other WDs and the average exposure of NWDs to WDs.

\footnotetext{
${ }^{4}$ We use 2019 ACS block groups rather than 2010 Census blocks as the 2010 Census is now significantly out-of-date. The results are similar if we instead use 2010 blocks.

${ }^{5} \mathrm{~A}$ ping is recorded each time a GPS device shares its location, while stays are aggregates of pings into individual stops at a location (with entry and exit times). For example, a visit to a grocery store may generate hundreds of pings but would only result in a single stay. We use the duration of a stay as a weight to approximate for the number of pings that were emitted during the stay. This still excludes time spent traveling between stays, which is included in ping-level measures from Athey et al. (2021).
} 
We make several assumptions in order to estimate Equation 2.1. First, we assume that $s(l(i, t), t)$ does not vary by time for a given location. ${ }^{6}$ Second, we assume that the full population of visits can be approximated using the device sample, re-weighted accordingly. Finally, we discretize locations by geohash7s (approximately $500 \times 500$ feet).

To estimate Equation 2.1, we first construct leave-one-out estimates of $s(\cdot)$ for each individuallocation as:

$$
\hat{s}_{l}^{-i}=\frac{\sum_{j \in P_{l}^{-i, \mathrm{WD}}} \gamma_{j} d_{j}}{\sum_{j \in P_{l}^{-i}} \gamma_{j} d_{j}}
$$

where $P_{l}^{-i}$ is the set of stays in location $l$ by devices besides $i, P_{l}^{-i \cap W D}$ is the set of stays in location $l$ by WDs, and $d_{j}$ is the duration of stay $j \cdot{ }^{7}$ Next, for each device-quarter in our sample we measure aggregate exposure as:

$$
\hat{S}_{i q}=\frac{1}{\sum_{j \in P_{i q}} d_{j}} \sum_{j \in P_{i q}} \hat{s}_{l}^{-i} d_{j}
$$

where $P_{i q}$ is the set of all stays by device $i$ in quarter $q$.

Finally, we estimate experienced isolation for a CBSA $a$ as:

$$
\hat{\mathrm{EI}}_{a}=\frac{1}{\left|\mathrm{WD}_{a}\right|} \sum_{i \in \mathrm{WD}} \sum_{q \in Q_{i}} \lambda_{i q} \hat{S}_{i q}-\frac{1}{\left|N \mathrm{WD}_{a}\right|} \sum_{i \in \mathrm{NWD}} \sum_{q \in Q_{i}} \lambda_{i q} \hat{S}_{i q}
$$

where $Q_{i}$ is the set of quarters in which device $i$ is observed and we abuse notation slightly to let $\mathrm{WD}_{a}$ be the set of all white device-quarters (rather than just devices) in geography $a$ and $\mathrm{NWD}_{a}$ be the corresponding set of non-white device-quarters. We use sample weights $\lambda_{i q}$ to correct for unevenness in the home locations of GPS sample compared to the ACS. We provide more details on these sample weights, which are used for all results in the paper, in Appendix Section A.4.

To estimate experienced isolation by student vs adult type, we estimate Equation 2.4 separately for each type. Note that the leave-one-out estimates of exposure remain the same, but only devices of a given type are used to aggregate exposure in Equation 2.4 - consequently, our experienced isolation measure for students measures exposure to both students and adults.

\footnotetext{
${ }^{6}$ This is most clearly violated in residential areas, where daytime and nighttime populations will differ substantially.

${ }^{7}$ We weight by duration in the location to approximate the ping-level measure used in Athey et al. (2020).
} 
Experienced isolation is defined at the population level - it is the difference in exposure to WDs by WDs and NWDs living in a CBSA. We also define a companion measure at the individual level, which we call experienced diversity. Experienced diversity for a given device is the average exposure to devices of the opposite imputed race and is estimated as

$$
\mathrm{ED}_{i q}=\frac{1}{\sum_{j \in P_{i q}} d_{j}} \sum_{j \in P_{i q}} \mathbb{1}\left\{\mathrm{NWD}_{i q}\right\} \hat{s}_{l}^{-i} d_{j}+\mathbb{1}\left\{\mathrm{WD}_{i q}\right\}\left(1-\hat{s}_{l}^{-i}\right) d_{j}
$$

where $\mathbb{1}\left\{\mathrm{WD}_{i q}\right\}$ and $\mathbb{1}\left\{\mathrm{NWD}_{i q}\right\}$ are indicators for whether the device's imputed race is white or non-white. As before, $\hat{s}_{l}^{-1}$ is the leave-one-out estimate of location l's share white, $d_{j}$ is the duration of stay $j$, and $P_{i q}$ is the set of all stays for device $i$ in quarter $q$. The two measures are closely linked - experienced isolation is a transformation of the average experienced diversity in a CBSA. ${ }^{8}$

\section{Experienced Isolation and Diversity of Students and Adults}

In this section, we first discuss overall experienced isolation and then turn to experienced diversity, our individual level component of experienced isolation. We end by discussing the broader patterns of mobility and interaction that we observe for adults and students.

\subsection{Experienced Isolation}

The leftmost column of panel (a) in Table 1 shows that overall experienced isolation is 0.65 , meaning that the average WD spends their time (on average) with 65 percentage points more WDs than the average NWD spends with WDs. The bulk of this isolation comes from the home itself experienced isolation outside the home drops to below 0.3 .

The second and third columns show the different experienced isolation of students and adults. Overall student isolation is 0.73 and adult isolation is 0.65 . When we exclude nighttime hours, the experience isolation of both groups falls, but there is still a significant difference between the groups. When we just look at isolation outside the home, the experienced isolation of adults is 0.288

\footnotetext{
${ }^{8}$ Experienced isolation can be computed from experienced diversity as $\mathrm{EI}=\left(1-\overline{\mathrm{ED}}_{\mathrm{WD}}\right)-\overline{\mathrm{ED}}_{\mathrm{NWD}}$, where $\overline{\mathrm{ED}}_{\mathrm{WD}}$ is the average experienced diversity of white devices and $\overline{E D}_{\mathrm{NWD}}$ is the average experienced diversity of NWDs.
} 
and the experienced isolation of students is 0.368. Excluding time near home, students experience roughly $27 \%$ more isolation than adults.

Panel (b) documents the time allocations of students and adults at different types of locations. Students spend $65 \%$ of their time at home, while adults spend $61 \%$ of their time at home. By contrast, adults spend $17 \%$ of their time at work while students spend $14 \%$ of their time at school. ${ }^{9}$ The other time use categories all represent much smaller time allocations. Adults spend more time at shops, restaurants, parks and entertainment venues. Students appear to spend more time at religious establishments. Adults also spend more time in the 'other' category, which can include travel, outdoor activities, or time visiting a neighbor's home.

Panel (b) also shows the experienced isolation for adults and students in each one of these categories. Every category is more isolated for students than adults. Time at home is particularly isolating - the isolation of students at home is 0.9 and the isolation of adults at home is 0.85 . In some cases, such as restaurants and entertainment venues, the experienced isolation gaps are relatively small (0.02 or less). In other areas, such as schools/workplaces or the other category, the gaps are quite sizable (0.07 or more). The higher aggregate isolation of students partially reflects the fact that adults spend more time at work than students spend at school, and that (childless) adults are more likely to live in areas that have visitors from different race neighborhoods.

In the Appendix, we document how these measures vary across individual CBSAs - Figure B.6 maps the overall experienced isolation and gap between students and adults for all CBSAs and Table B2 provides the raw numbers. While the levels of experienced isolation differ substantially across CBSAs, the experienced isolation of students is higher than that of adults in nearly all of the largest CBSAs. ${ }^{10}$ The gap between student and adult experienced isolation is especially highabout 10 percentage points - in the CBSAs of the largest American cities, including New York City, Chicago, and Los Angeles. In Appendix Section B.3, we also discuss the relationship between our measures and enrollment-based school isolation measures from Logan et al. (2017).

\footnotetext{
${ }^{9}$ The American Time Use Survey (ATUS) reports that adults spent $14 \%$ of their time working. The discrepancy can be explained by the fact that we identify place of work as an individual's most common daytime destination, and so everyone in our sample has a place of work.

${ }^{10}$ The three exceptions are El Paso, TX, McAllen-Edinburg-Mission, TX, and Durham-Chapel Hill, NC
} 
Table 1: Experienced isolation of students and adults

\begin{tabular}{|c|c|c|c|c|}
\hline \multicolumn{2}{|l|}{ Panel a) Overall experienced isolation (EI) } & Aggregate & Students & Adults \\
\hline All hours & & 0.6535 & 0.7321 & 0.6512 \\
\hline Excluding night time (12am-6am) & & 0.5677 & 0.6243 & 0.5661 \\
\hline Excluding time at home $(<150 \mathrm{~m})$ & & 0.2910 & 0.3679 & 0.2883 \\
\hline Excluding time in home tract & & 0.2631 & 0.3325 & 0.2605 \\
\hline \multirow[t]{2}{*}{ Panel b) EI by location category } & \multicolumn{2}{|c|}{ Students } & \multicolumn{2}{|c|}{ Adults } \\
\hline & $\%$ of hours & EI & $\%$ of hours & EI \\
\hline Home & 65.389 & 0.902 & 61.022 & 0.851 \\
\hline School/work & 14.180 & 0.354 & 17.217 & 0.283 \\
\hline Retail & 0.339 & 0.214 & 0.554 & 0.194 \\
\hline Restaurant & 0.316 & 0.188 & 0.442 & 0.168 \\
\hline Entertainment & 0.475 & 0.159 & 0.506 & 0.144 \\
\hline Park & 0.572 & 0.284 & 0.606 & 0.242 \\
\hline Religious organization & 0.075 & 0.319 & 0.062 & 0.282 \\
\hline Other & 18.265 & 0.388 & 19.311 & 0.308 \\
\hline Panel c) Individual exposure to diversity & Average & $\begin{array}{l}\text { Coefficient on isStudent } \\
\text { (Home CBSA controls) }\end{array}$ & $\begin{array}{l}\text { Coefficie } \\
\text { (Home }\end{array}$ & $\begin{array}{l}\text { Student } \\
\text { ontrols) }\end{array}$ \\
\hline \multicolumn{5}{|l|}{ All } \\
\hline Exposure to diversity & 0.125 & $\begin{array}{l}-0.0386 \\
(0.0002)\end{array}$ & & $\begin{array}{l}-0.0264 \\
(0.0002)\end{array}$ \\
\hline Exposure to NWD by WD & 0.1001 & $\begin{array}{l}-0.0353 \\
(0.0002)\end{array}$ & & $\begin{array}{l}-0.0239 \\
(0.0002)\end{array}$ \\
\hline Exposure to WD by NWD & 0.1645 & $\begin{array}{l}-0.0341 \\
(0.0003)\end{array}$ & & $\begin{array}{l}-0.0294 \\
(0.0003)\end{array}$ \\
\hline \multicolumn{5}{|l|}{ Excluding time at home $(<150 m)$} \\
\hline Exposure to diversity & 0.2631 & $\begin{array}{l}-0.0529 \\
(0.0003)\end{array}$ & & $\begin{array}{l}-0.0377 \\
(0.0003)\end{array}$ \\
\hline Exposure to NWD by WD & 0.2087 & $\begin{array}{l}-0.0534 \\
(0.0003)\end{array}$ & & $\begin{array}{l}-0.0411 \\
(0.0003)\end{array}$ \\
\hline Exposure to WD by NWD & 0.3496 & $\begin{array}{l}-0.0303 \\
(0.0005)\end{array}$ & & $\begin{array}{l}-0.0309 \\
(0.0004)\end{array}$ \\
\hline
\end{tabular}

Note: This table documents overall experienced isolation measures, computed as a weighted average of CBSA-level measures, with weights corresponding to the CBSA population. Panel a) documents the overall level of experienced isolation. 'At home' is defined as within 150 meters of home location. Panel b) splits the experienced isolation measures by categories of locations visited. Panel c) runs individual-quarter regressions of exposure to diversity on whether the device is a student with either home CBSA or home Census tract fixed effects. 


\subsection{Exposure to Diversity}

Table 1, Panel (c), focuses on the individual-level measure, exposure to diversity. This is useful for decomposing the difference between students and adults into a residential location component and a within neighborhood component. Overall exposure to diversity is 0.125 , meaning $12.5 \%$ of the average device's interactions are with devices of the opposite inferred race. ${ }^{11}$ The second and third rows break this measure out for WDs and NWDs. White exposure to diversity is 0.10, while non-white exposure to diversity is 0.16 . This large gap partially reflects the fact that there are many more devices that we categorize as white.

In the middle and right columns, we report the coefficient on whether a device is a 'student' in two separate regressions. In the regressions associated with the middle column, we control for metropolitan area fixed effects. In those for the right column, we control for tract fixed effects. The middle column therefore answers the question of whether students are disproportionately isolated relative to adult residents of their metropolitan area. The right column asks if students are more isolated that adults who live in their neighborhoods. The middle column reveals more about the overall isolation of students, since conditioning on place of residence is essentially controlling for a major determinant of individual isolation.

All six coefficients in these columns are significant and negative. In the first row of the panel, we find that exposure to diversity is 0.039 points lower for students than for adults, which is approximately $30 \%$ of the sample mean. The estimated student coefficient drops in magnitude to -0.026 when we include tract of residence fixed effects. This fact suggests that one-third of the difference in exposure to diversity between students and adults is due to the different home locations of students. Outside the home, students have about $20 \%$ less exposure to devices of the opposite race than adults. In the second and third rows, we split up the sample by imputed race and find quite similar results.

In the bottom of Table 1, Panel (c), we report results on exposure to diversity outside the home. Since race is imputed based on residential location, exposure to diversity is artificially low within the

\footnotetext{
${ }^{11}$ If both WDs and NWDs experienced a diversity exposure of 0.125 , then the implied isolation measure is 0.75 , which is higher than our measure of isolation. Experienced isolation is computed at the CBSA-level and then aggregated by taking the population weighted average, which yields slightly different results than averaging exposure to diversity at the individual-level as smaller metropolitan areas are generally less segregated than larger areas.
} 
home as all residents are assigned the same race. When we exclude time spent at home, exposure to diversity increases to 0.26 in aggregate (0.21 for WDs and 0.35 for NWDs). The overall student exposure to diversity outside the home is $20 \%$ lower than adult exposure to diversity when we control for metropolitan area, and $14 \%$ lower when we control for tract of residence. In the bottom two rows, we find that exposure outside the home is lower for WDs than for NWDs, which reflects that whites are the overwhelming majority in most metropolitan areas. For WDs, student exposure to diversity is over $25 \%$ lower than adult exposure to diversity when we control for metropolitan area and $20 \%$ lower than adult exposure when we control for tract of residence. The gap between adult and student exposure to diversity is lower for NWDs, but it is still statistically significant and economically meaningful. Controlling for either tract or metropolitan area, we find that the exposure of NWDs to diversity is about $8 \%$ lower for students than for adults.

\section{Broader Mobility Patterns of Students and Adults}

We now turn to broader patterns of urban mobility between adults and students. We report measures of the distances they travel, the time spent at home and work/school, and the characteristics of the areas that they visit. We then turn to the links between density and urban mobility.

\subsection{Broader Mobility Patterns of Students and Adults}

Table 2 looks at patterns of mobility between students and adults. We document a general pattern of adults being more mobile than students. The first two rows of Panel (a) mirror results that have already been shown in Table 1 - adults spend less time at home than students and more time at work than students spend at school. The results with home tract controls show that the time gaps found in Table 1 are not the result of residential location.

Rows (3)-(5) show that adults are generally more mobile than students. Students are more likely to spend time close to their homes, even when they are not in their homes, while adults are more likely to travel more than $>50$ miles away from home. Even when we restrict to days when devices remain with within 50 miles of their residence, adult devices travel further afield than 
student devices. These facts could be explained by the greater prevalence of car ownership among adults and by adults commuting further for work than students commute for school.

The last five lines in Panel (a) all focus on the number of visits to different types of establishments. These results differ from those in Table 1 because they focus on the number of different trips, not total time spent in each category. The first column gives the mean absolute number of these visits. We report mean levels because they are useful for comparison, but since devices are not observed all the time, they do not provide a true count of trips. The second and third columns provide coefficients from regressions on an indicator for student device in which the dependent variable is the inverse hyperbolic sine of the number of visits in each category.

The mean number of observed restaurant visits per quarter is 1.4, with students having about $7 \%$ fewer visits than adults. The mean number of observed retail store visits is 2.0 per quarter, with students having more than $16 \%$ fewer visits than adults. These results parallel those in Table 1, which found that adults spent more time at restaurants and retail locations. While adults also spend slightly more time at parks and entertainment venues that students, students make more trips to such places. The average number of observed park visits was 1.4, and students have about $7 \%$ more park visits than adults. The average number of observed entertainment-related trips was also 1.4, and students have $8.3 \%$ more of these trips. These results suggest that students make slightly more short trips to these locations.

The final row of Panel (a) reports the number of unique locations visited in a quarter. We observe student phones going to about $8 \%$ more unique locations than adults, holding metropolitan areas fixed. When we control for Census tract of residents, the gap drops to about $4 \%$, suggesting that students live in places where people tend to be more mobile. Even though students spend more time in the house, they go to more unique places when they do travel, which is compatible with a view that students' lives are somewhat less routinized than adults.

In bottom panel, we look at the characteristics of the Census tracts where adults and children travel, excluding time at home or work. The first three rows show demographic characteristics of residents. All three demographic variables show a similar pattern. Students are generally exposed to richer, better educated, and whiter neighborhoods. For all three of these outcomes, however, 
the coefficients fall by more than half once we control for tract of residence. Indeed, the coefficients for both race and education become quite small with these controls. The implication seems to be that childless adults live in neighborhoods that are close to poorer areas, perhaps because they are more likely to live closer to work and less likely to live near wealthier suburban neighborhoods.

The fourth row shows air pollution, measured by the presence of particulates with diameters smaller than 2.5 micrometers. The air pollution regressions show that children typically face less pollution than adults in their metropolitan area, but more pollution than adults who live in their Census tract, although the magnitudes are small in both cases. In the last row, we look at exposure to crime, but we can do this only for Chicago and Los Angeles where we have neighborhood-level crime data. Adults are exposed to far more crime than children, but the coefficient drops by more than one-half when we control for tract of residence. Again, both results may be explained by parents choosing somewhat healthier neighborhoods than other adults.

These results looked at aggregate differences in urban mobility of students and adults living in the top 100 CBSAs. We now turn to differential patterns by geography - specifically, by density of residence within a CBSA. We focus on density, because it is the defining feature of cities and because density is a strong negative correlate of upward mobility for urban children (Glaeser and Tan, 2021).

\subsection{Density and urban mobility}

To examine the relationship between population density and mobility, we use the within-CBSA density decile for each device's home block group. Consequently, we are not estimating a constant treatment effect of physical density but rather the impact of a relatively higher density level within a metropolitan area. Notably, in both our sample of GPS devices as well as in the ACS, students disproportionately live in the less dense, more suburban parts of cities. $3.7 \%$ of devices in the least dense decile are students compared to $2.4 \%$ in the most dense decile (see Appendix Figure A.2).

Figure 1 plots how certain mobility outcomes vary by within-CBSA density. To construct the figure, we regress each outcome on home density decile interacted with whether the device is a student, controlling for metropolitan area fixed effects. We also control for the log household 
Table 2: Urban mobility of students and adults

\begin{tabular}{|c|c|c|c|}
\hline & $\begin{array}{c}\text { Average } \\
\text { (not logged) }\end{array}$ & $\begin{array}{l}\text { Coef. on isStudent } \\
\text { (Home CBSA FEs) }\end{array}$ & $\begin{array}{l}\text { Coef. on isStudent } \\
\text { (Home tract FEs) }\end{array}$ \\
\hline \multicolumn{4}{|l|}{ Device-quarter level outcomes } \\
\hline Frac. of time at home & 0.6395 & $\begin{array}{r}0.0391 \\
(0.0003)\end{array}$ & $\begin{array}{r}0.0345 \\
(0.0003)\end{array}$ \\
\hline Frac. of time at work/school & 0.1738 & $\begin{array}{r}-0.027 \\
(0.0002)\end{array}$ & $\begin{array}{l}-0.0231 \\
(0.0002)\end{array}$ \\
\hline Frac. time $<1 \mathrm{mi}$ from home (excl. home) & 0.0552 & $\begin{array}{r}0.0164 \\
(0.0002)\end{array}$ & $\begin{array}{r}0.0186 \\
(0.0002)\end{array}$ \\
\hline Frac. of days over $50 \mathrm{mi}$ from home & 0.0697 & $\begin{array}{l}-0.0254 \\
(0.0002)\end{array}$ & $\begin{array}{l}-0.0263 \\
(0.0002)\end{array}$ \\
\hline Avg miles from home & 7.4075 & $\begin{array}{l}-0.3238 \\
(0.0011)\end{array}$ & $\begin{array}{l}-0.3639 \\
(0.0011)\end{array}$ \\
\hline Log \# restaurant visits & 1.4723 & $\begin{array}{l}-0.0604 \\
(0.0014)\end{array}$ & $\begin{array}{l}-0.0761 \\
(0.0014)\end{array}$ \\
\hline Log \# retail visits & 2.0087 & $\begin{array}{l}-0.1601 \\
(0.0015)\end{array}$ & $\begin{array}{l}-0.1827 \\
(0.0015)\end{array}$ \\
\hline Log \# park visits & 1.4133 & $\begin{array}{r}0.0704 \\
(0.0011)\end{array}$ & $\begin{array}{r}0.0576 \\
(0.0011)\end{array}$ \\
\hline Log \# entertainment visits & 1.388 & $\begin{array}{r}0.0832 \\
(0.0015)\end{array}$ & $\begin{array}{r}0.048 \\
(0.0015)\end{array}$ \\
\hline Log \# unique locations (geohash7) & 41.2958 & $\begin{array}{r}0.081 \\
(0.0014)\end{array}$ & $\begin{array}{r}0.0379 \\
(0.0013)\end{array}$ \\
\hline \multicolumn{4}{|l|}{ Characteristics of tracts visited } \\
\hline Log median $\mathrm{HH}$ income & 75845 & $\begin{array}{r}0.0829 \\
(0.0008)\end{array}$ & $\begin{array}{r}0.0381 \\
(0.0006)\end{array}$ \\
\hline Frac. college graduate & 0.3902 & $\begin{array}{r}0.0102 \\
(0.0004)\end{array}$ & $\begin{array}{r}0.0012 \\
(0.0002)\end{array}$ \\
\hline Frac. White alone & 0.5794 & $\begin{array}{r}0.0315 \\
(0.0004)\end{array}$ & $\begin{array}{r}0.0078 \\
(0.0003)\end{array}$ \\
\hline Air quality (PM25) & 8.6467 & $\begin{array}{r}-0.026 \\
(0.0016)\end{array}$ & $\begin{array}{r}0.0079 \\
(0.0012)\end{array}$ \\
\hline Log crimes per sq. mi. (Chicago \& Los Angeles) & 9.711 & $\begin{array}{l}-0.1973 \\
(0.0159)\end{array}$ & $\begin{array}{l}-0.0709 \\
(0.0085)\end{array}$ \\
\hline
\end{tabular}

Note: The table documents coefficients from regressions of mobility metrics on whether the device is a student with fixed effects for either the device's home CBSA of Census tract. Miles from home is the average distance of stays outside of the home on days the device stayed within 50 miles of home, weighted by the stay duration. 'At home/work/school' is defined as within 150 meters of the location's coordinates. We use data on the average estimated tract-level air pollution in 2019 from the Environmental Protection Agency (EPA). For the crime outcomes, we subset to just devices that live within those city boundaries and measure crime as the sum of all crimes reported between 2010-2018 in a tract. The characteristics of tracts visited results exclude time spent at home or work/school. To handle zeros, we use the inverse hyperbolic sine instead of the logarithm. Both the averages and regressions use the device weights; for tract outcomes, the regressions are also weighted by time spent in the tract. Standard errors are clustered at the device-quarter level. 
median income and fraction white alone in the device's home tract to narrow in on the correlation with home density, holding fixed race and income. ${ }^{12}$ We normalize the intercept for adults at the first decile to be the mean outcome for adults at that decile.

The first panel shows that adults who live in denser areas spend less time at home than adults in less dense areas. This fits the view that in urban areas, apartments are smaller and people are more likely to go out to eat or drink or find entertainment or work longer hours. The opposite is true for children, who spend more of their time at home when they live in denser areas. Panel (b) shows the mirror of this result for time spent at work or school. Density is associated with more time at work for adults and less time at school for students, while students in the densest block groups spend about one percentage point less time at school than those in the least dense.

Panel (c) shows the number of unique locations visited, which declines with density for both students and adults. The decline with density is quite dramatic for students and quite mild for adults. In the least decile, students visit far more unique locations than adults. In the most dense decile, however, adults visit more unique locations than students. This is striking, since one might expect the greater availability of public transit to be a force in the opposite direction. However, density seems associated with living more geographically compact lives, especially for students.

Finally, panel (d) shows the education of residents of the tracts in which students and adults spend time outside of the home. This increases for both students and adults generally; however, in the densest of areas of the cities, there is a sizeable drop for students relative to adults.

Appendix Figure B.4 includes the relationship between mobility and density for additional outcomes, such as the number of restaurants visited (which increases for adults, but not students). Overall, we find that geographic mobility varies substantially with density within metropolitan areas, that trends often differ between students and adults, and that the densest deciles often have trend reversals. We now turn to the final section of the paper that concerns the correlation between geographic mobility and income mobility.

\footnotetext{
${ }^{12}$ Appendix Figure B.5 repeats these regressions without controls for income and race.
} 
Figure 1: Mobility outcomes and density

(a) Frac. time at home

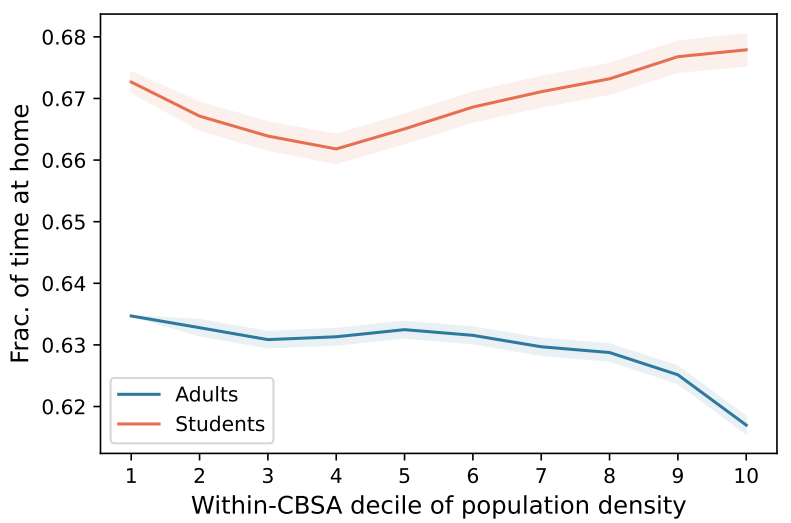

(c) Log \# unique locations

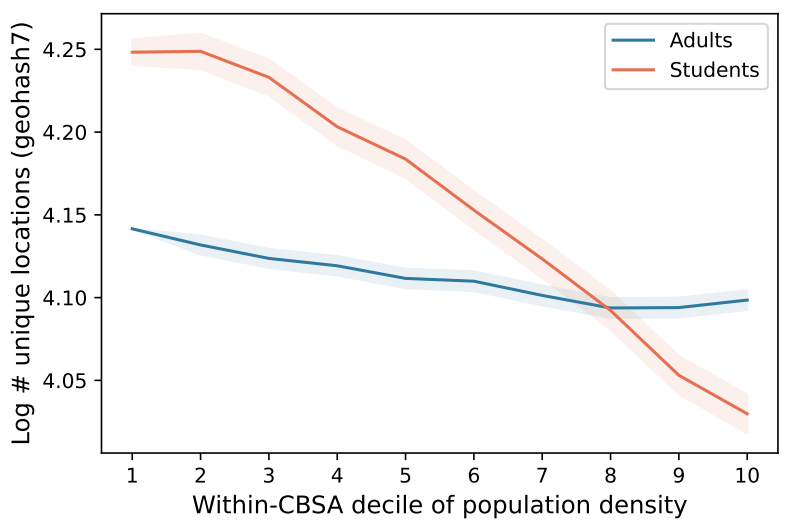

(b) Frac. time at work/school

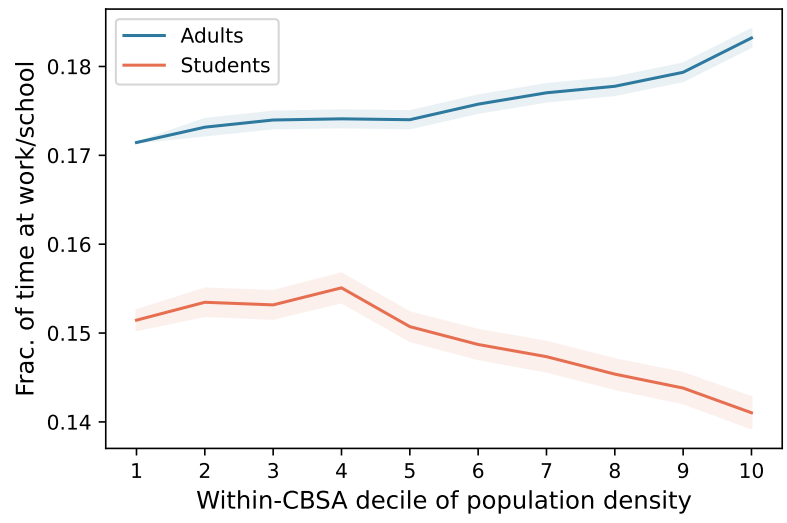

(d) Frac. college grad of visited tracts

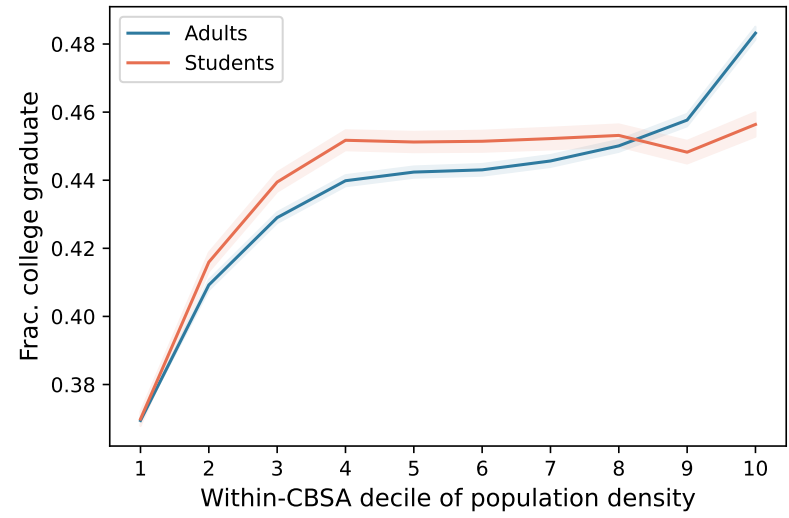

Note: This figure plots the relationship between urban mobility and density. We regress each outcome on the interaction between within-CBSA decile of home block group density and whether the device is a student, with fixed effects for the CBSA and controls for log median household income and fraction white alone. Panels a)-c) use device-quarter level data, while panel d) uses data on all tracts visited within a given device-quarter. Coefficients are computed relative to adults in the least dense decile and the Y-axis is shifted by the average outcome for adults in the least dense decile. Standard errors are clustered at the device-quarter level. The shaded region represents a $95 \%$ confidence interval.

\section{Correlations with Upward Mobility}

As we discussed in Section II, we use data on upward mobility from the Opportunity Atlas, which is detailed in Chetty et al. (2018). We first focus on majority non-white tracts, and we use the estimated income mobility for children whose parents were at the 25 th percent of the income distribution at the time of the child's birth. There is a significant temporal mismatch of more than 20 years between our data and the Opportunity Atlas data, which capture people who would have 
been 17 years old around 1997. Consequently, these results could easily reflect the impact of income mobility on geographic mobility rather than of geographic mobility on income mobility.

Our results are summarized in Figure 2. In all cases, we report results where income mobility is regressed on geographic mobility. Each panel shows 12 coefficients taken from 12 separate regressions, for six different types of geographic mobility. Panel (a) shows regression results for majority non-white tracts, which include CBSA fixed effects but no other tract-level controls. Panel (b) adds tract-level controls for fraction white in the tract, log of population density, log of median age, and the share of residents enrolled in school. Panel (c) reports results for all tracts, not just those that are majority non-white.

In almost every case, the coefficient on mobility of students is closer to zero than the coefficient on the mobility of adults. The most natural explanation for this fact is that there are far fewer students than adults and consequently our tract-level measures of the mobility of students have more measurement error, which could lead to attenuation bias.

The share of time spent at home, work and school are rarely correlated with upward mobility, but in all three specifications, time that adults spend in the neighborhood is negatively associated with upward mobility. While we have controlled for density in panels (b) and (c), this variable may still be capturing aspects of suburban life which appear to be positively associated with opportunity the Opportunity Atlas data.

The last three measures of geographic mobility - days spent outside the city, unique locations visited, and exposure to diversity — are positively correlated with income mobility in all three figures, using data for both adults and students. In the first two panels, exposure to diversity has the strongest correlation with upward mobility. Earlier research shows that residential segregation is negatively associated with upward mobility (Chetty and Hendren, 2018). The correlation between exposure to diversity and income mobility in Figure 2 provides suggestive evidence that experienced isolation is also associated with less upward mobility. The number of unique locations visited by adults is also strongly associated with upward mobility in all three panels. These facts are compatible with the view that mixing is associated with escaping poverty, but future work will need to address the possibility that the causality is running in the opposite direction. 
Figure 2: Income mobility and urban mobility

(a) Majority non-white tracts. Controls: CBSA FEs

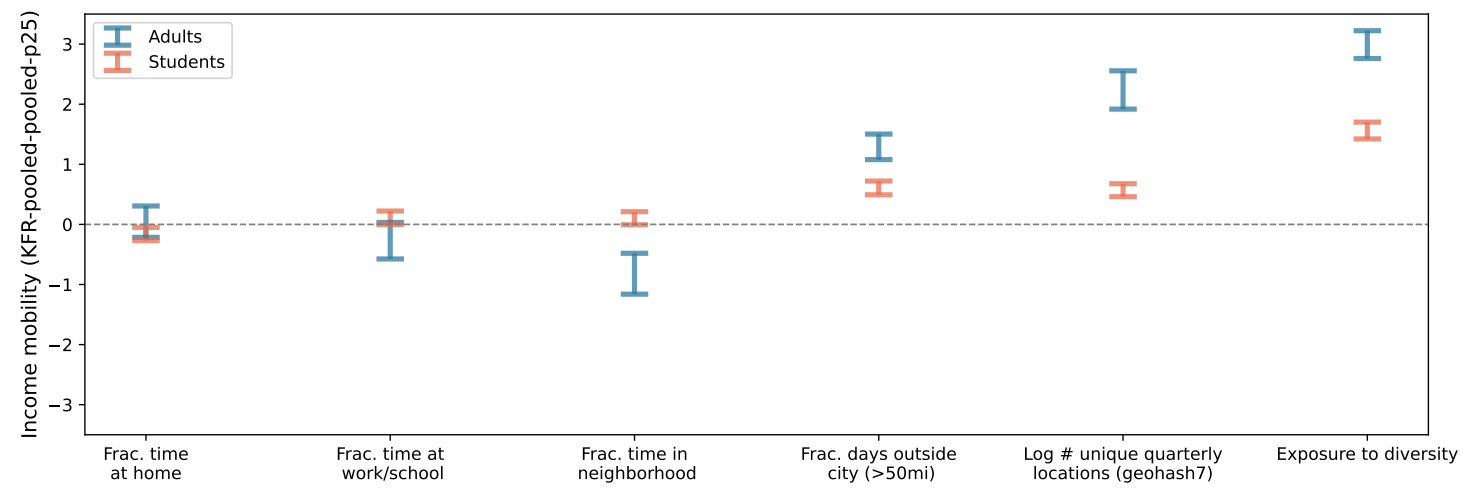

(b) Majority non-white tracts. Controls: CBSA FEs and tract characteristics

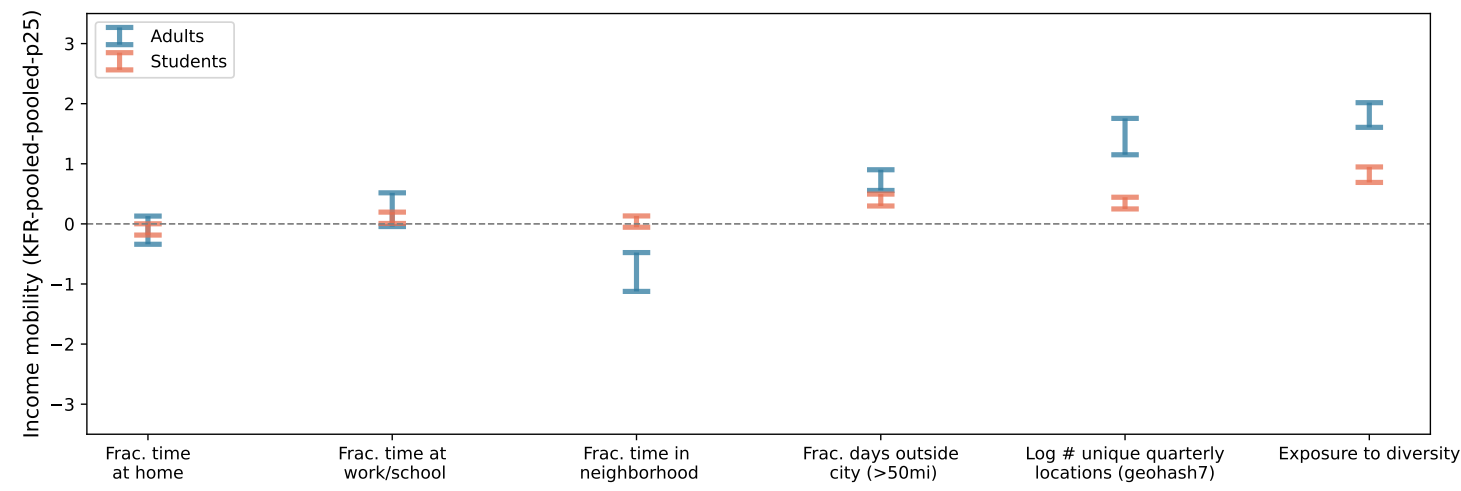

(c) All tracts. Controls: CBSA FEs and tract characteristics

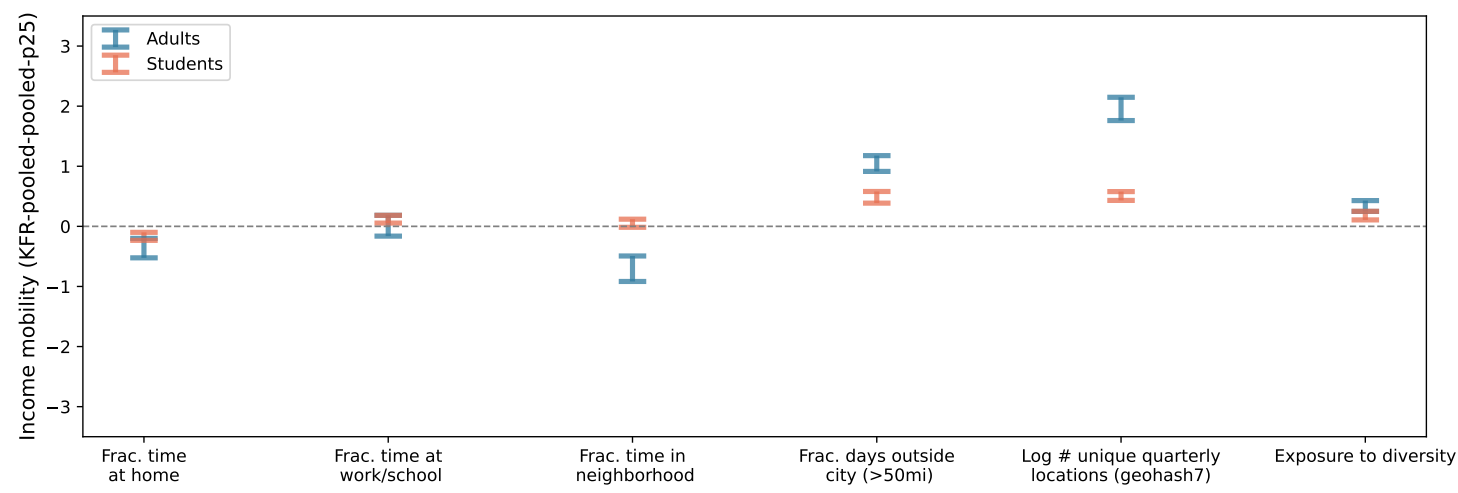

Note: This figure plots coefficients from tract-level regressions of opportunity and urban mobility measures for students and adults, with fixed effects for CBSAs. Controls for tract characteristics include fraction white alone, log population density, log median age, and the fraction of residents enrolled in school. The regressions for students and results are run separately and exclude any tracts with 5 or fewer student devices. Opportunity is measured by the absolute income mobility for students born to parents in the 25th percentile of income - a value of 1 implies an increase of one percentage point in the income distribution. Each regression is weighted by the number of households in that tract who are below the 25th nationwide income percentile. Effects are standardized to be for a one standard deviation increase in the urban mobility measure for each groups. Each bar represents a $95 \%$ confidence interval. 


\section{Conclusion}

In this paper, we address the hypothesis that adults and students experience different levels of segregation, even if they live in the same neighborhood. We follow the methods of Athey et al. (2021) to measure 'experienced isolation' of students and adults. Our primary innovation is to look at the experienced isolation and overall urban mobility of adults and students separately.

Despite the fact that our 'student' devices will also include teachers and other school staff, we find significant differences in the experienced isolation and urban mobility of adults and students. Overall isolation is $12 \%$ higher for students than for adults and isolation when outside the home is $27 \%$ higher for students. Overall exposure to diversity is $30 \%$ lower for students than for adults when controlling for metropolitan areas. Even when comparing devices who live in the same tract, exposure to diversity is $20 \%$ lower for students. These results support the hypothesis that the urban young live far more isolated lives than adults, which may explain why cities appear to increase wage growth for adults but reduce income mobility for children (Glaeser and Tan, 2021).

Looking at broader measures of urban mobility, we find that students spend more time at home than adults, especially when they live in the densest parts of metropolitan areas. Moreover, even when outside the home, students spend their time closer to home and travel outside the city on fewer days. Adults spend more time at work than students spend at school, and their workplaces tend to be more integrated than students' high schools. Students do, however, spend their time in more prosperous and better-educated — but also less diverse — neighborhoods than adults.

Finally, we find the slightest suggestion of evidence that these forms of isolation are associated with lower levels of upward income mobility. Using measures of income mobility from Chetty and Hendren (2018), we find positive correlations between upward income mobility and exposure to diversity, time spent away from the city, and number of unique locations visited. However, we caution that these correlations are stronger for the adult measures than for the student measures, and income mobility is assessed for a cohort that is roughly forty years old at the time of our geographic mobility measures. We hope that future research will assess the connection between urban mobility and income mobility more thoroughly. 


\section{References}

Athey, Susan, Billy Ferguson, Matthew Gentzkow, and Tobias Schmidt, "Experienced Segregation," Technical Report w27572, National Bureau of Economic Research, Cambridge, MA July 2020.

$\ldots, \ldots, \ldots$, and $\ldots$, "Estimating experienced racial segregation in US cities using large-scale GPS data," Proceedings of the National Academy of Sciences, 2021, 118 (46).

Cagney, Kathleen A, Erin York Cornwell, Alyssa W Goldman, and Liang Cai, "Urban mobility and activity space," Annual Review of Sociology, 2020, 46, 623-648.

Chetty, Raj and Nathaniel Hendren, "The Impacts of Neighborhoods on Intergenerational Mobility I: Childhood Exposure Effects*," The Quarterly Journal of Economics, August 2018, $133(3), 1107-1162$.

_, John N Friedman, Nathaniel Hendren, Maggie R Jones, and Sonya R Porter, "The opportunity atlas: Mapping the childhood roots of social mobility," Technical Report, National Bureau of Economic Research 2018.

Cutler, David M and Edward L Glaeser, "Are ghettos good or bad?," The Quarterly Journal of Economics, 1997, 112 (3), 827-872.

Glaeser, Edward and Brandon Tan, "Why are cities good for adults but bad for children?," Harvard University mimeograph, 2021.

Glaeser, Edward L and David C Mare, "Cities and skills," Journal of labor economics, 2001, $19(2), 316-342$.

Logan, John R, Elisabeta Minca, and Sinem Adar, "The geography of inequality: Why separate means unequal in American public schools," Sociology of education, 2012, 85 (3), 287301.

_, Weiwei Zhang, and Deirdre Oakley, "Court orders, white flight, and school district segregation, 1970-2010," Social Forces, 2017, 95 (3), 1049-1075.

Orfield, Gary, Sara Schley, Diane Glass, and Sean Reardon, "The growth of segregation in American schools: Changing patterns of separation and poverty since 1968," Equity ES Excellence in Education, 1994, 27 (1), 5-8. 
Roca, Jorge De La and Diego Puga, "Learning by working in big cities," The Review of Economic Studies, 2017, 84 (1), 106-142. 


\section{A Data appendix}

\section{A.1 GPS data}

The GPS data come from an unbalanced panel of GPS-enabled devices in 2019. Home and work locations are identified by Replica based on heuristics for when individuals tend to be at home versus work. Home location is generally the most common overnight location in a quarter, while work locations is generally the most common non-home daytime location. ${ }^{13}$

To identify stays at different types of establishments, we use data from SafeGraph on the locations of various Points of Interest (POIs). The establishments data include the polygon describing the establishment's footprint. We use this polygon to identify when a device visits a given establishments. For establishments located within a larger, parent location (e.g., a restaurant within a mall), we assign the parent location rather than trying to disambiguate the individual establishment.

We categorize establishments according to their North American Industry Classification System (NAICS) code. Restaurants are those with NAICs codes beginning with '722'. Retail locations are those establishments with NAICS codes beginning with '44' or '45'. Parks, while not establishments, are identified in SafeGraph with a NAICS codes of '712190'. Entertainment locations are all nonpark POIs with a NAICS code beginning with '71'. Finally, religious organizations are those with NAICS codes beginning with ' 8131 '.

\section{A.2 Building a sample of schools}

The schools data comes from the National Center for Education Statistics (NCES). However, NCES data only includes the school address, name, grades served, and enrollment. Moreover, the address is often a PO box or simply the town center rather than the actual school location. To match NCES schools to parcels, we first match each school to Safegraph data on schools using the school's name and location. The Safegraph data includes precise coordinates for each school as well as polygons. Unfortunately, the Safegraph polygons - which are often automatically generated from satellite imagery - are inaccurate for schools; for large schools with multiple building, the polygon

\footnotetext{
${ }^{13}$ We require devices to have at least 8 overnights and 5 days at work in the quarter to make the sample.
} 
will generally only include a single building. We instead match the Safegraph coordinates to parcel-level data from LandGrid. These parcels come from local municipalities and provide more accurate boundaries for school locations. In total, $82 \%$ of schools representing $88 \%$ of enrollment are successfully matched to a parcel.

Figure A.1 plots the relationship between a school's enrollment and the number of devices we label as a student at that school - the two counts of students are highly correlated. Figure A.2 plots the percent of residents who are students in the GPS sample as well as the percent who are in grades 9-12 in the 2019 5-year ACS. Students predominantly live in the less dense areas of the city. The overall trend is true in both the ACS and GPS, although we consistently find fewer high school (HS) students in the GPS data than in the ACS. This could be due to a number of factors, including 1) many HS students are under 16 years old and 2) we cannot match all schools to parcel polygons.

Figure A.1: NCES school enrollment \& number of devices in sample

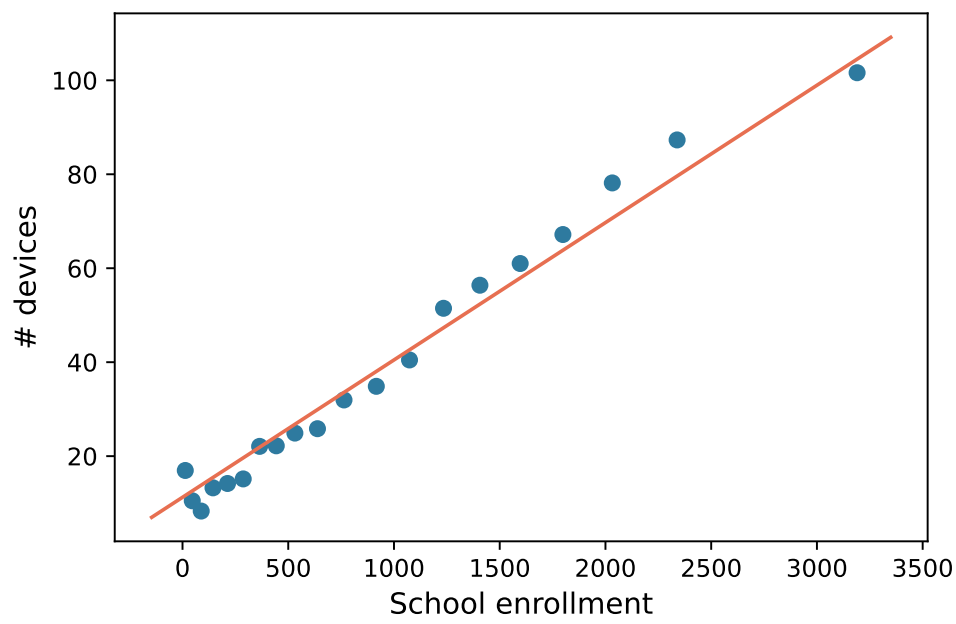

Note: This figure plots the relationship between the enrollment of a school as reported by the NCES and the number of devices labeled as a student of that school.

\section{A.3 Sample quality}

Figure A.3 plots the fraction of devices who live in each decile of tract characteristics - if sampling were orthogonal to tract characteristics, $10 \%$ of devices would be sampled from each decile. Instead, 
Figure A.2: Percent of residents who are students by density

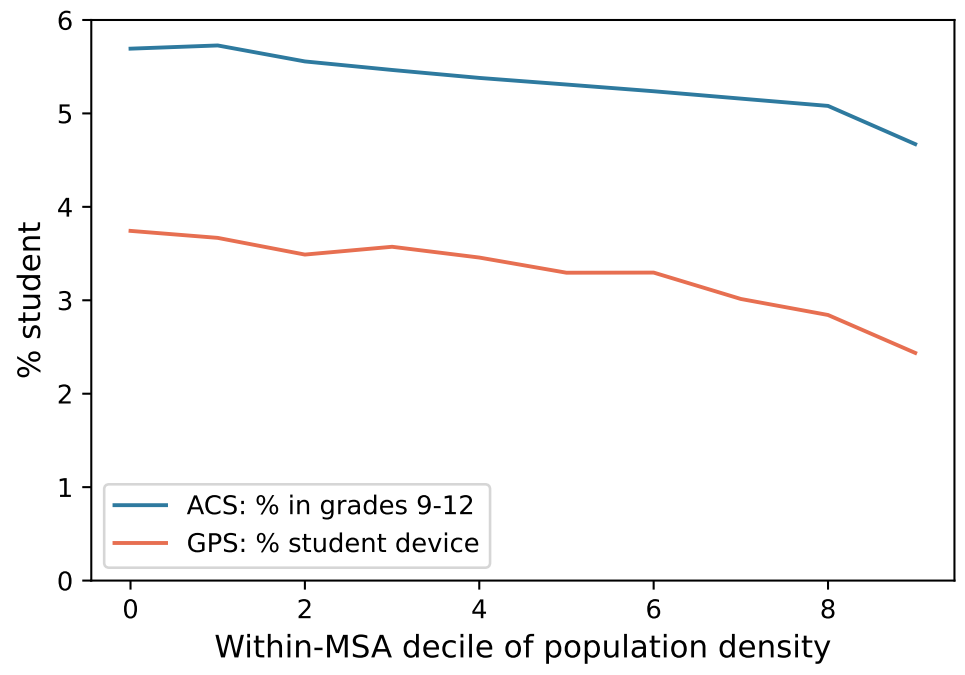

Note: This figure plots the percent of residents who are students by within-CBSA home block group density. We separately plot the percent student in the GPS sample as well as the percent in grades 9-12 in the 2019 5-year ACS.

we can see that devices are over-sampled from poorer, less white, less educated, and more dense areas.

Figure A.4 plots the distribution of block group fraction white-alone (non-Hispanic). The average block group of white devices is $78.5 \%$ white, while the average block group of non-white devices is $21.0 \%$ white.

\section{A.4 Sample Weights}

GPS devices in our sample tend to be slightly over-sampled from poorer, less white, less educated, and more dense areas (see Appendix Figure A.3). To address the uneven sampling of devices, we re-weight home locations to match the distribution of the 2019 5-year ACS by using the following sample weights

$$
\lambda_{i q}=\frac{N_{g(i q)}}{\tilde{N}_{g(i q)}}
$$

where $N_{g(i q)}$ is the ACS population of a device's home tract $g$ and $\tilde{N}_{g(i q)}$ is the total number of devices observed in tract $g$ in quarter $q$. The average device weight is 20.2 (standard deviation of 12.9). We use these weights for all results. 
Figure A.3: Sampling of devices by block group characteristics
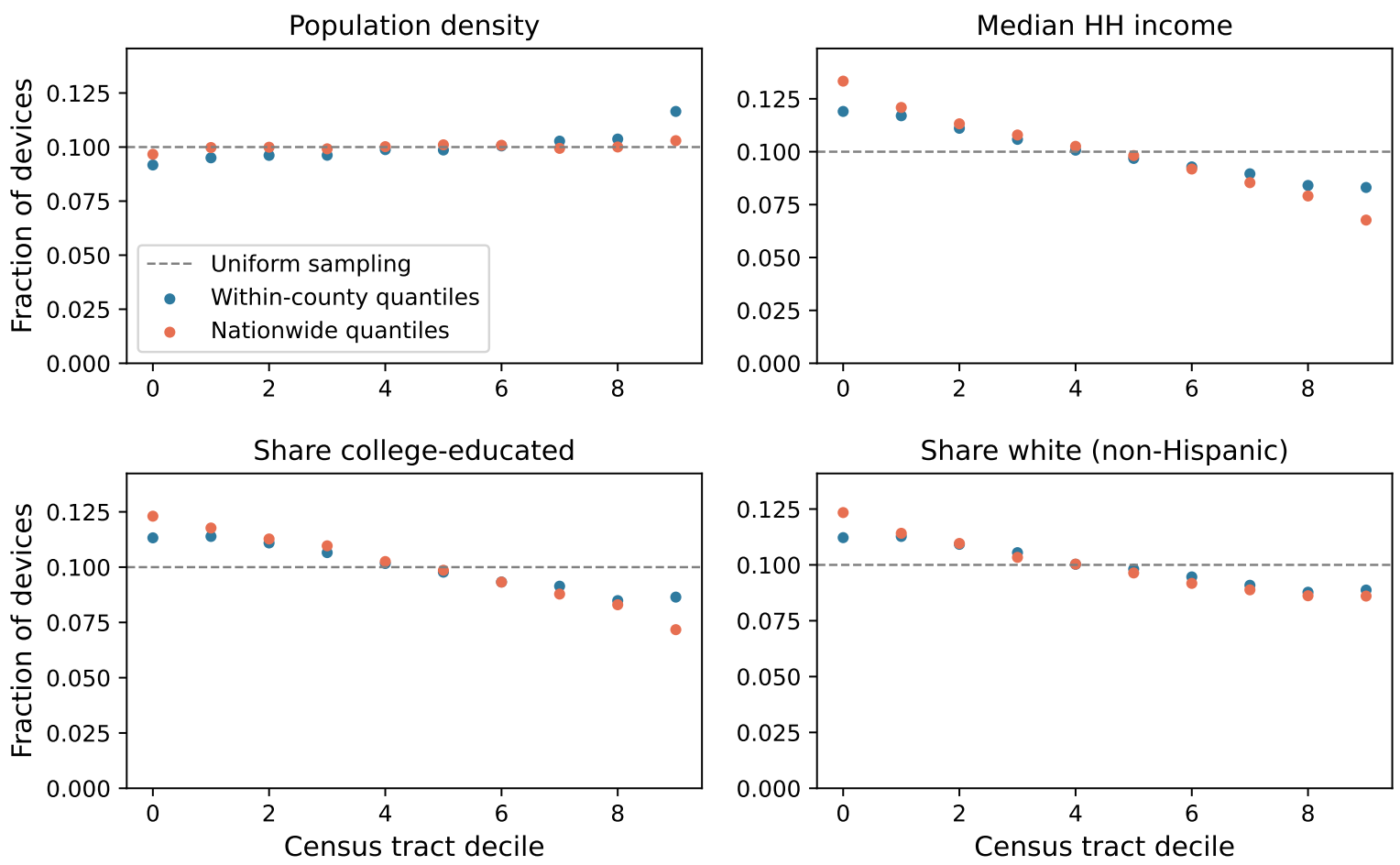

Note: This figure plots the relationship between the enrollment of a school as reported by the NCES and the number of devices labeled as a student of that school.

Figure A.4: Distribution of block group level fraction white

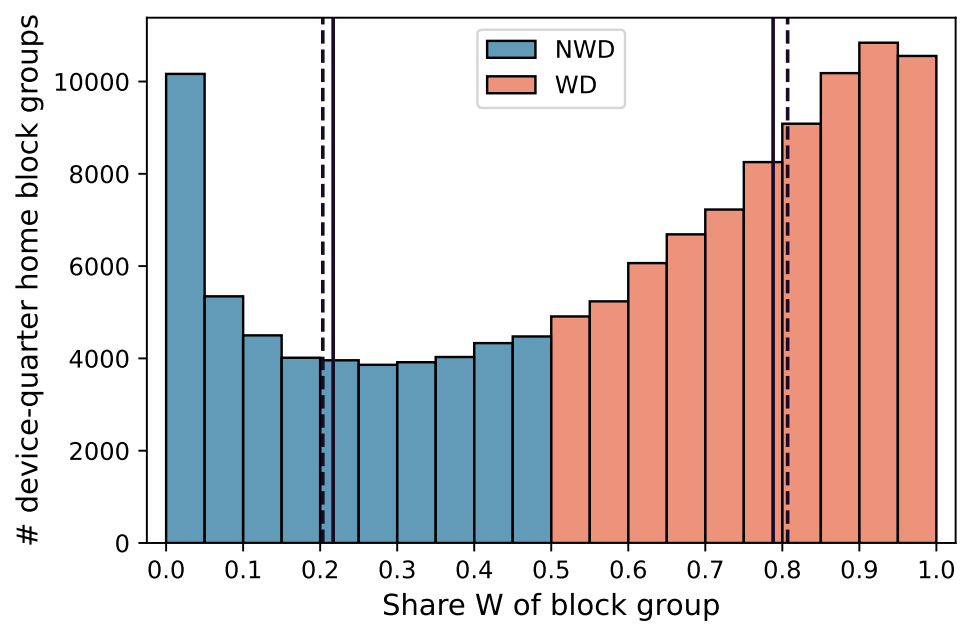

Note: This figure plots a histogram of the number of the number of devices sampled from different bins of home block group fraction white alone (non-Hispanic). The solid line represents the mean fraction white for each WD and NWD; the dashed line is the median. 


\section{B Additional results on the mobility of students \& adults}

\section{B.1 Experienced isolation with continuous race}

Our baseline measure of experienced isolation uses a binary measure of race - as in Athey et al. (2020) — based on whether a device's home block group is majority white non-Hispanic or not. We also explore assigning devices a continuous measure of race using the percent of their home block group that is white. Using this continuous measure of race, we can estimate experienced isolation as

$$
\hat{E} I_{a}^{C}=\frac{1}{\left|W_{a}\right|} \sum_{i} \sum_{q \in Q_{i}} \rho_{i q} \lambda_{i q} \hat{S}_{i q}-\frac{1}{\left|N W_{a}\right|} \sum_{i} \sum_{q \in Q_{i}}\left(1-\rho_{i q}\right) \lambda_{i q} \hat{S}_{i q}
$$

where $\rho_{i q}$ is the continuous measure of race, $\left|W_{a}\right|=\sum_{i} \sum_{q \in Q_{i}} \lambda_{i q} \rho_{i q}$, and $\left|N W_{a}\right|=\sum_{i} \sum_{q \in Q_{i}} \lambda_{i q}(1-$ $\left.\rho_{i q}\right)$

The results are in Table B1. Using this measure, students are $4.12 \%$ more isolated in aggregate and $17.6 \%$ more isolated when outside of the home. However, the levels are dramatically different.

Experienced isolation with continuous race will be biased downwards relative to 'true' exposure to diversity. Imagine a device whose true exposure to white individuals is $100 \%$. When using a continuous measure of race, each exposure to a white individual will not count as a fully segregated exposure but instead will assume the device is exposed to the average percent white in the individual's home block group, making it look like the device has more diverse exposures than it does. Similarly, a device whose true exposure is $0 \%$ white will have a positive estimated exposure.

Table B1: Experienced isolation using continuous measure of race

\begin{tabular}{lrrr}
\hline Panel a: experienced isolation & Aggregate & Student & Adult \\
\hline All & 0.2134 & 0.2248 & 0.2123 \\
Excluding time at home & 0.1141 & 0.1370 & 0.1129 \\
Excluding time in home tract & 0.1060 & 0.1274 & 0.1050 \\
\hline
\end{tabular}

Note: This table documents a few basic measures of experienced isolation using a continuous measure of race based on the percent non-white in a device's home block group 


\section{B.2 Exposure to diversity and home block group race}

Figure B.1 plots the relationship between percent white in a device's home block group and the device's exposure to diversity. This figure is constructed in a similar manner to those in Figure 1, by regressing exposure to diversity for a given device-quarter on whether the device is a student, interacted with the percent of their home block group's residents who are white (truncated to nearest 10\%). Recall that exposure to diversity uses WD and NWD, rather than true race; as such, devices in racially mixed block groups still have exposure to diversity well below $50 \%$.

Figure B.1: Exposure to diversity by home block group percent white

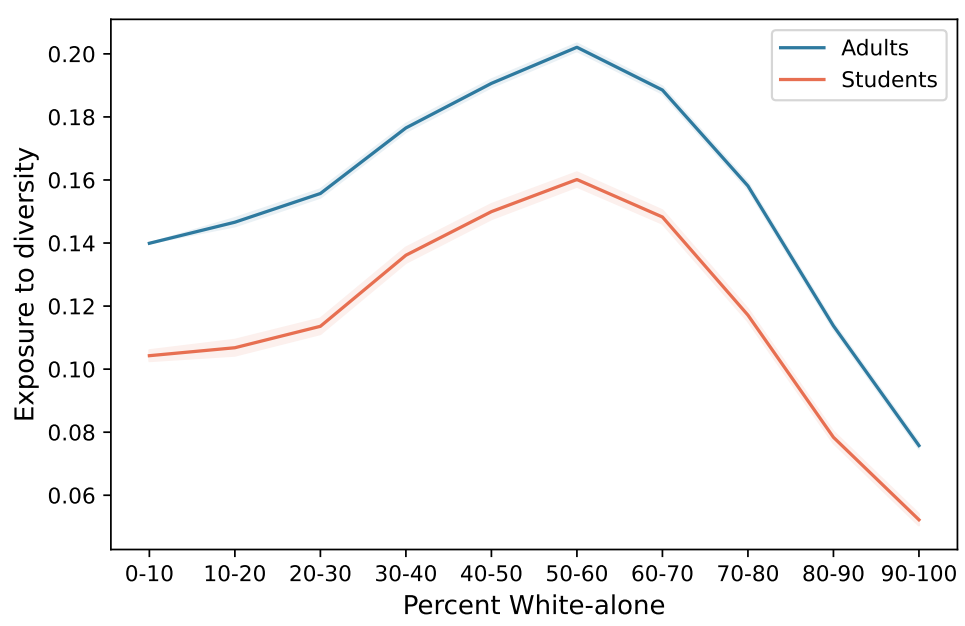

Note: This figure documents how exposure to diversity varies by the racial composition of a device's home block group.

The figure is constructed by regressing exposure to diversity for a given device-quarter on whether the device is a student, interacted with the percent of their home block group's residents who are white (truncated to nearest $10 \%$ ).

The shaded region represents a $95 \%$ confidence interval

\section{B.3 Experienced isolation and school dissimilarity}

Figure B.2 compares measures of segregation from GPS data at the MSA-level to the dissimilarity indices from Logan et al. $(2012,2017)$ for the top 50 MSAs. The first measure is the experienced isolation of students while at school, while the second is the dissimilarity of WD/NWD school populations within a CBSA, intended to be analogous to the measure in Logan et al. Dissimilarity is defined as the percentage of students in one group who would have to move to a different school to achieve a racial balance representative of the MSA. The GPS measures and the Logan 
measure are positively correlated, which is encouraging, but there are also clear differences. These differences are perhaps expected for a number of reasons: 1) the dissimilarity indices are based on 2010 elementary school enrollment while the experienced isolation is based on 2019 high school students; 2) the dissimilarity indices compare white students and either Black or Hispanic, while we are comparing students from majority white and non-white neighborhoods; 3) our data will include some teachers; 4) the dissimilarity indices are defined either for MSAs or PMSAs instead of CBSAs, so the geographic match is imperfect (e.g., the results for Chicago are comparing the Chicago PMSA and the Chicago-Joiliet-Naperville CBSA).

Figure B.2: GPS measures vs. elementary school dissimilarity

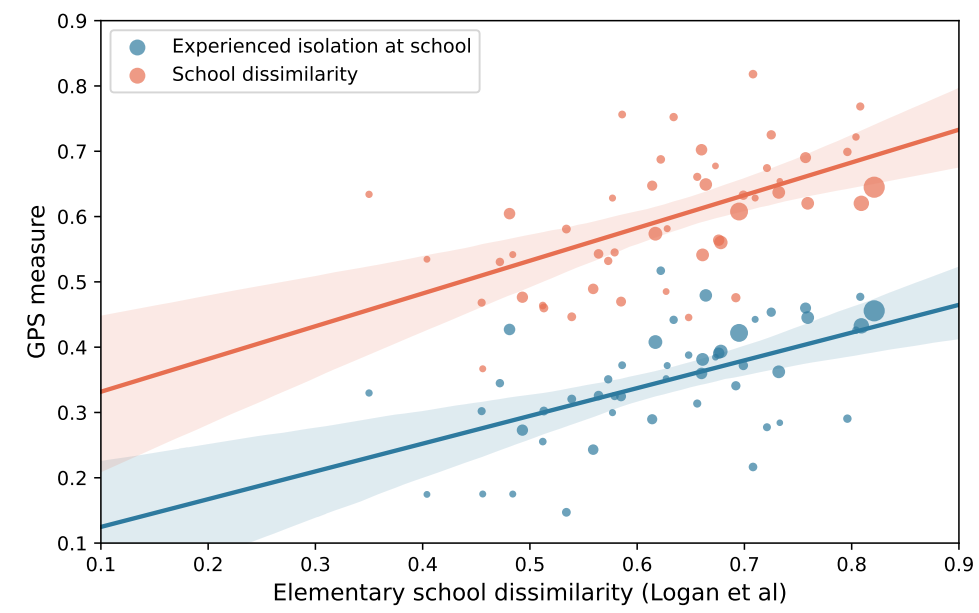

Note: Figure B.2 compares MSA-level experienced isolation of students while at school and dissimilarity of school populations of WD/NWD to the dissimilarity indices from Logan et al. $(2012,2017)$. The dissimilarity indices are based on 2010 elementary school enrollment from NCES. Correlation for EI is 0.55 and for dissimilarity is 0.56 .

\section{B.4 Experienced isolation and residential isolation}

Figure B.3 plots the relationship between an CBSA's experienced and residential isolation, splitting experienced isolation by whether or not a device is within its home tract. The relationship is plotted for both binary and continuous race and can help highlight the differences of each type of race assignment. For binary race, the time at home is estimated to be extremely isolatedgenerally far above residential isolation-because devices are spending the majority of their time in a home parcel where all other devices have the same, binary race. Meanwhile, for continuous 
race, experienced isolation is approximately equal to residential isolation while in the home tract. This is because experienced isolation with continuous race and residential are making a similar underlying assumption - interactions in the home tract are (approximately) with the average race of that location. ${ }^{14}$

For the majority of CBSAs, we estimate that experienced isolation is higher than residential isolation. This is counter to the findings in Athey et al. (2020). We believe that the discrepancies stem from differences in data construction. Athey et al. (2020) use raw GPS pings, which are recorded each time an app on the device connects to GPS, while we use staypoints, which are aggregations of pings into 'stays' in a given location. In Athey et al. (2020), a unit of 'exposure' to a neighborhood is therefore at the ping level, while in our measure we weight by staypoint minutes in a location.

The use of stays instead of pings leads to larger estimates of experienced isolation for two reasons, both related to how time spent at home affects the aggregate measure. First, using pings puts less weight on time spent at home. Devices are less likely to ping overnight while the holder is sleeping; however, a staypoint is still formed from the evening to the morning. Athey et al. (2020) report that $42.5 \%$ of pings are at home for the average device (their Table A3), while devices in our sample are at home for $63.9 \%$ of minutes observed. Excluding night time stays, for example, substantially reduces our measure of experienced isolation, although it remains higher than residential isolation (Table 1).

The second reason is that exposure when using pings will include devices walking/driving through the location, while staypoints include only those devices that stop for at least 5 minutes in a location. This difference is particularly noticeable for residential locations - the experienced isolation in Athey et al. (2020) of 'at home' pings is 0.672 (Table A9), which is lower than expected given that, by definition, all devices who live in that geohash7 are assigned the same race. This low number is likely due to devices who walk/drive through the location during the day, who are more diverse than the residents. The assumption that the time people visit a location is independent

\footnotetext{
${ }^{14}$ The measures differ for two reasons: 1) with experienced isolation, race is measured at the block group rather than tract level and 2) interactions in the home block group include outside visitors, although for residential tracts the majority of interactions are with other residents.
} 
of their race is violated in the case of residences where night-time and day-time populations differ substantially.

While the home-based assignment of race makes it difficult to compare experienced and residential isolation directly, we find that individuals experience far less isolation outside of the home tract than they do within their home tract, as discussed in Athey et al. (2020). Experienced isolation outside of the home tract is also substantially lower than residential isolation. Moreover, we do not believe the home-based assignment affect the relative differences in either measure of isolation for students and adults.

Figure B.3: Experienced vs. residential isolation

(a) Binary race

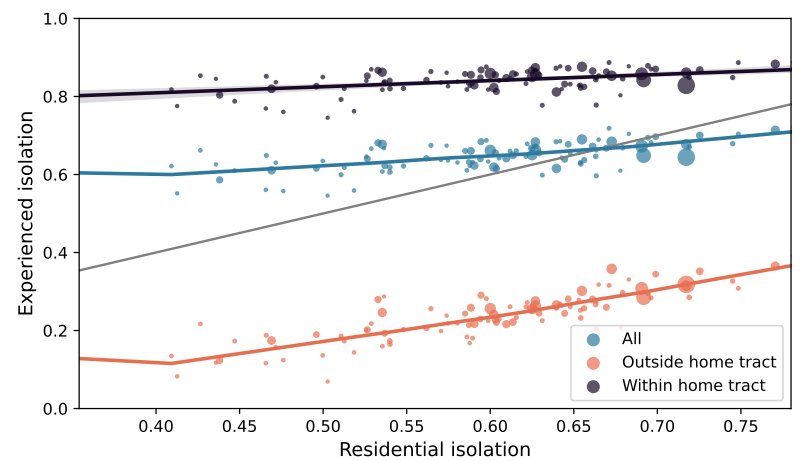

(b) Continuous race

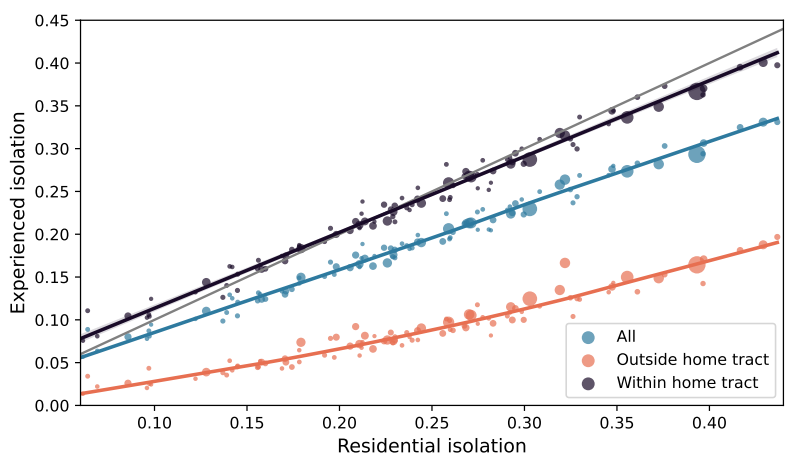

Note: Each figure plots the relationship between experienced isolation and residential isolation at the MSA level. Residential isolation is estimated to be consistent with the method of estimating experienced isolation; it uses either binary block-group level race or continuous race.

\section{B.5 Additional tables and figures}


Figure B.4: Mobility outcomes and density - other outcomes

(a) Exposure to diversity

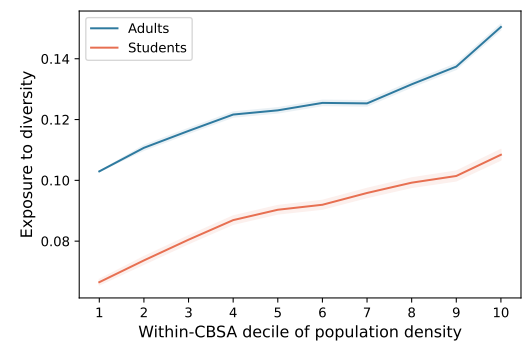

(d) Log \# retail visits

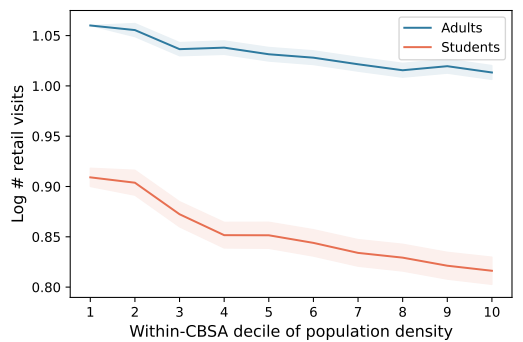

(b) Frac. time in neighborhood

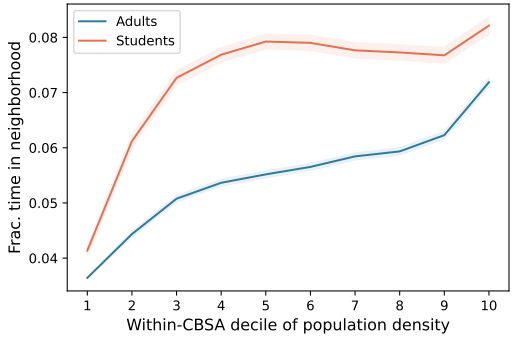

(e) Log \# restaurant visits

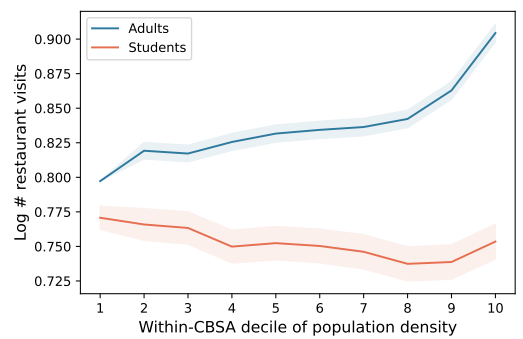

(c) Frac. days outside of city

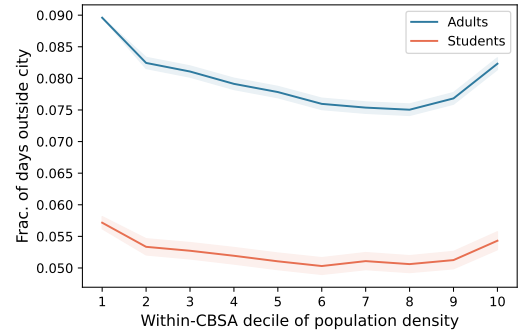

(f) $\log \#$ entertainment visits

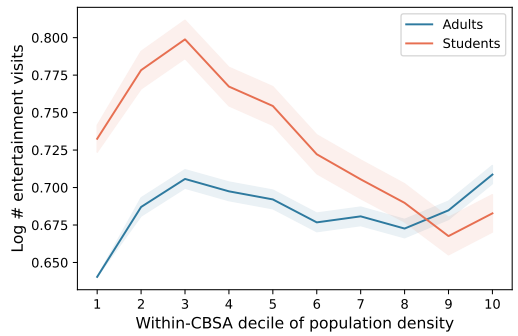

Note: This figure extends Figure 1 to additional mobility outcomes. To deal with zeros, we use an inverse hyperbolic sine transformation rather than logarithm. We exclude controls for home tract income and fraction white in panels g) and h). 
Figure B.5: Mobility outcomes and density - no controls

(a) Frac. time at home

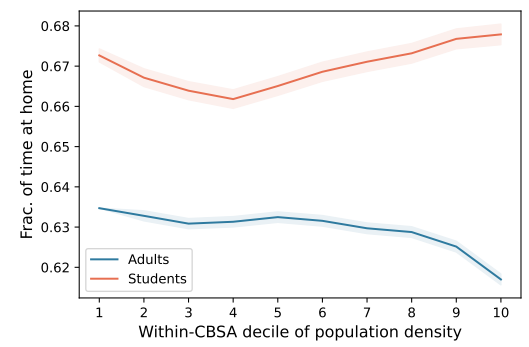

(d) Frac. college grad of visited tracts

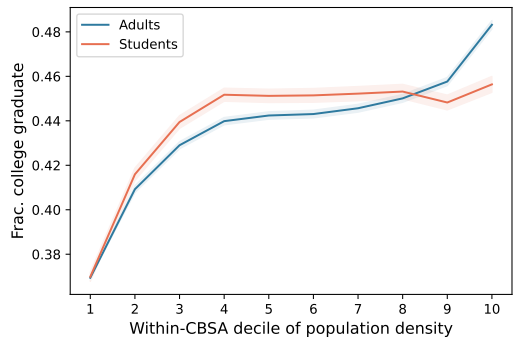

(g) Frac. days outside of city

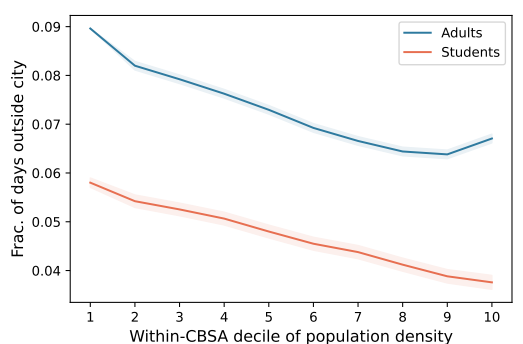

(j) Log \# entertainment visits

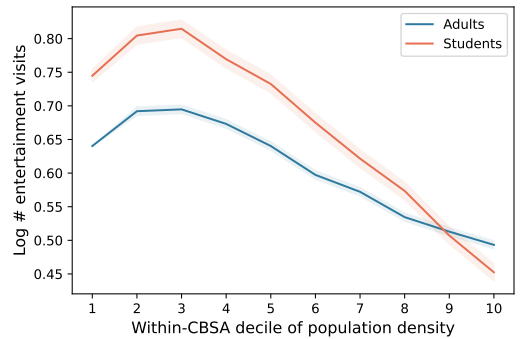

(b) Frac. time at work/school

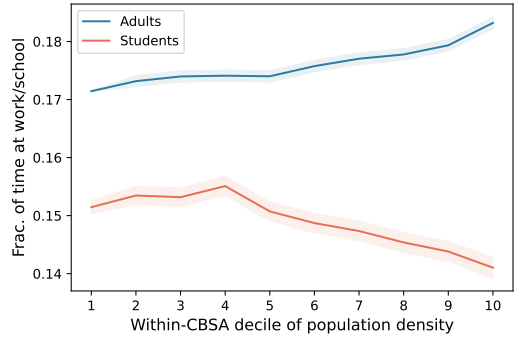

(e) Exposure to diversity

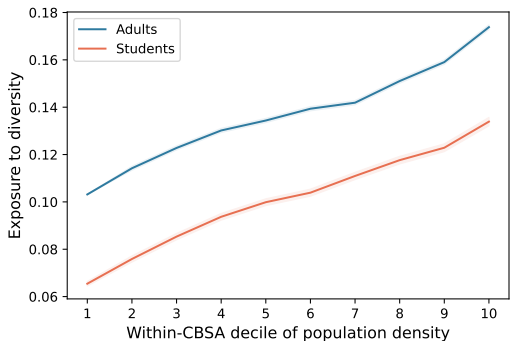

(h) Log \# retail visits

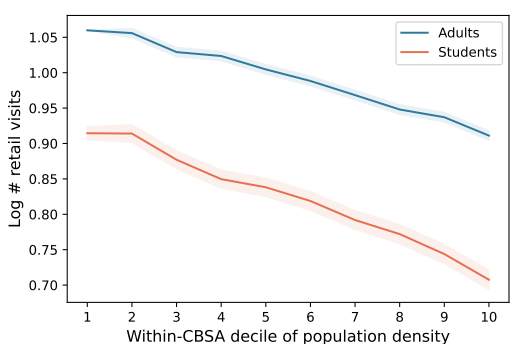

(k) Tract log median $\mathrm{HH}$ income

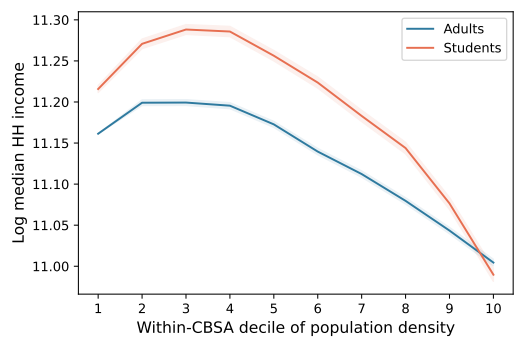

(c) Log \# unique locations

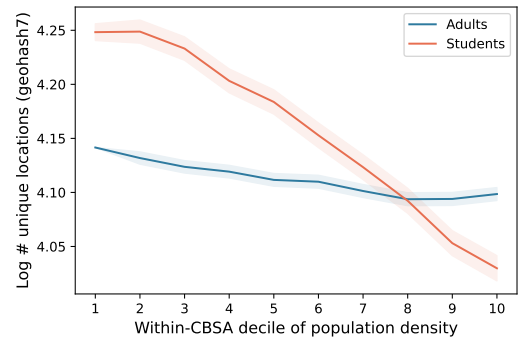

(f) Frac. time in neighborhood

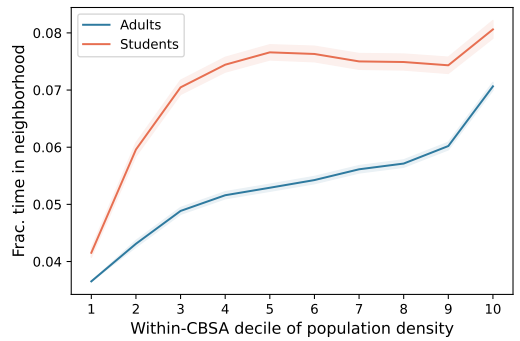

(i) Log \# restaurant visits

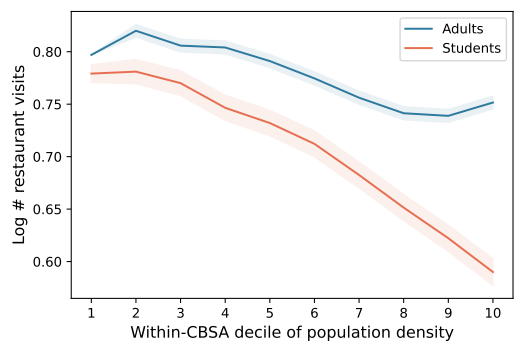

(1) Tract frac. white alone

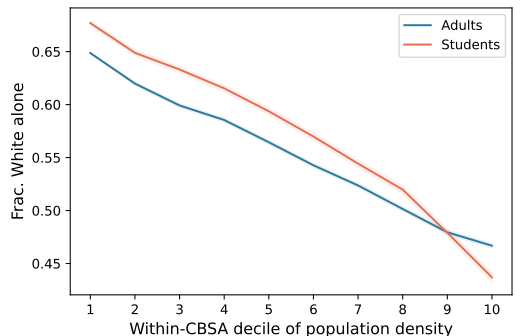

Note: This figure replicates Figures 1 and B.4 without any controls for home characteristics, except home CBSA. This figure also includes two other tract-level outcomes (without controls). To deal with zeros, we use an inverse hyperbolic sine transformation rather than logarithm. 
Figure B.6: Experienced isolation by CBSA

(a) Aggregate

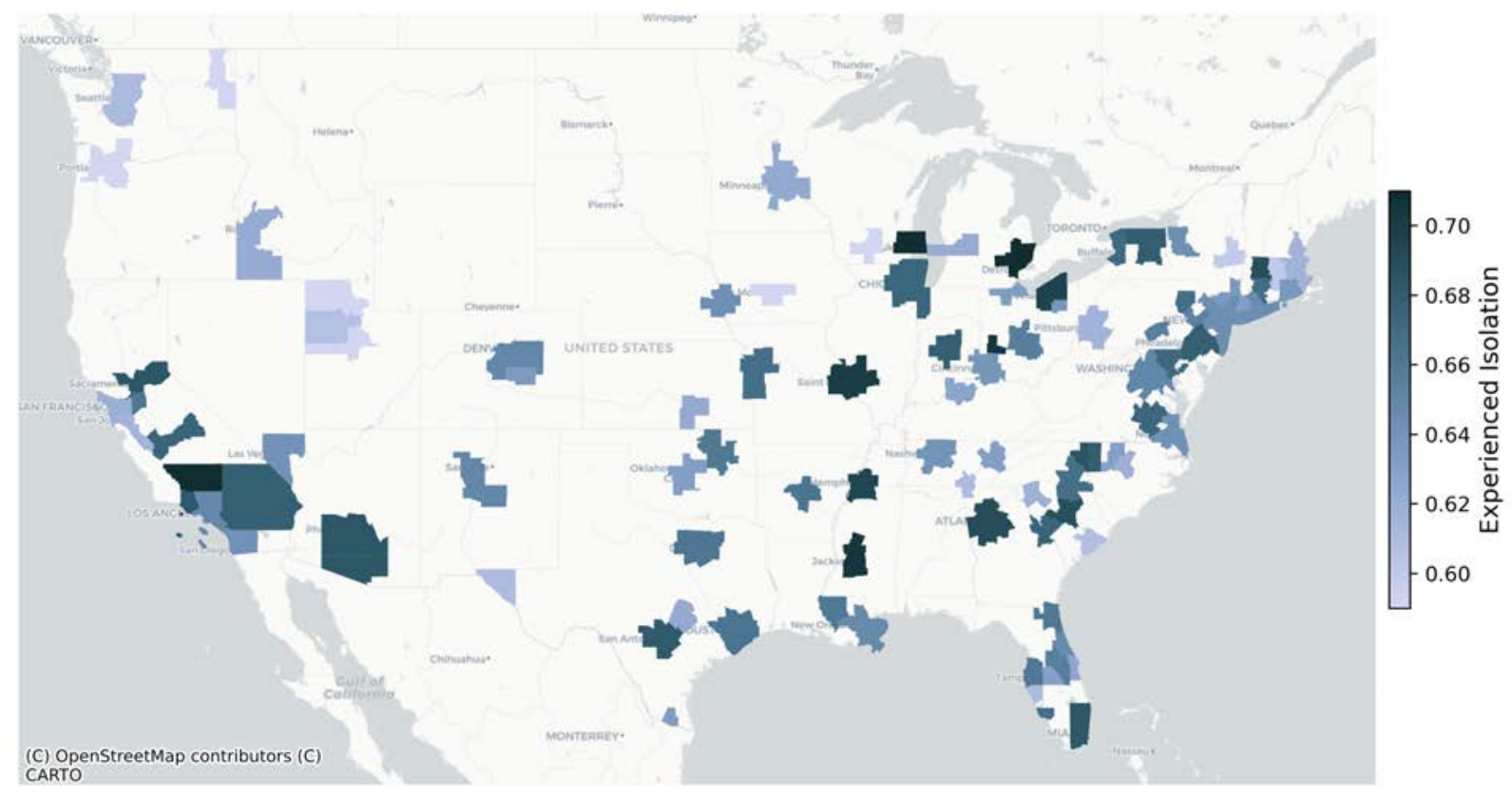

(b) Difference between students and adults

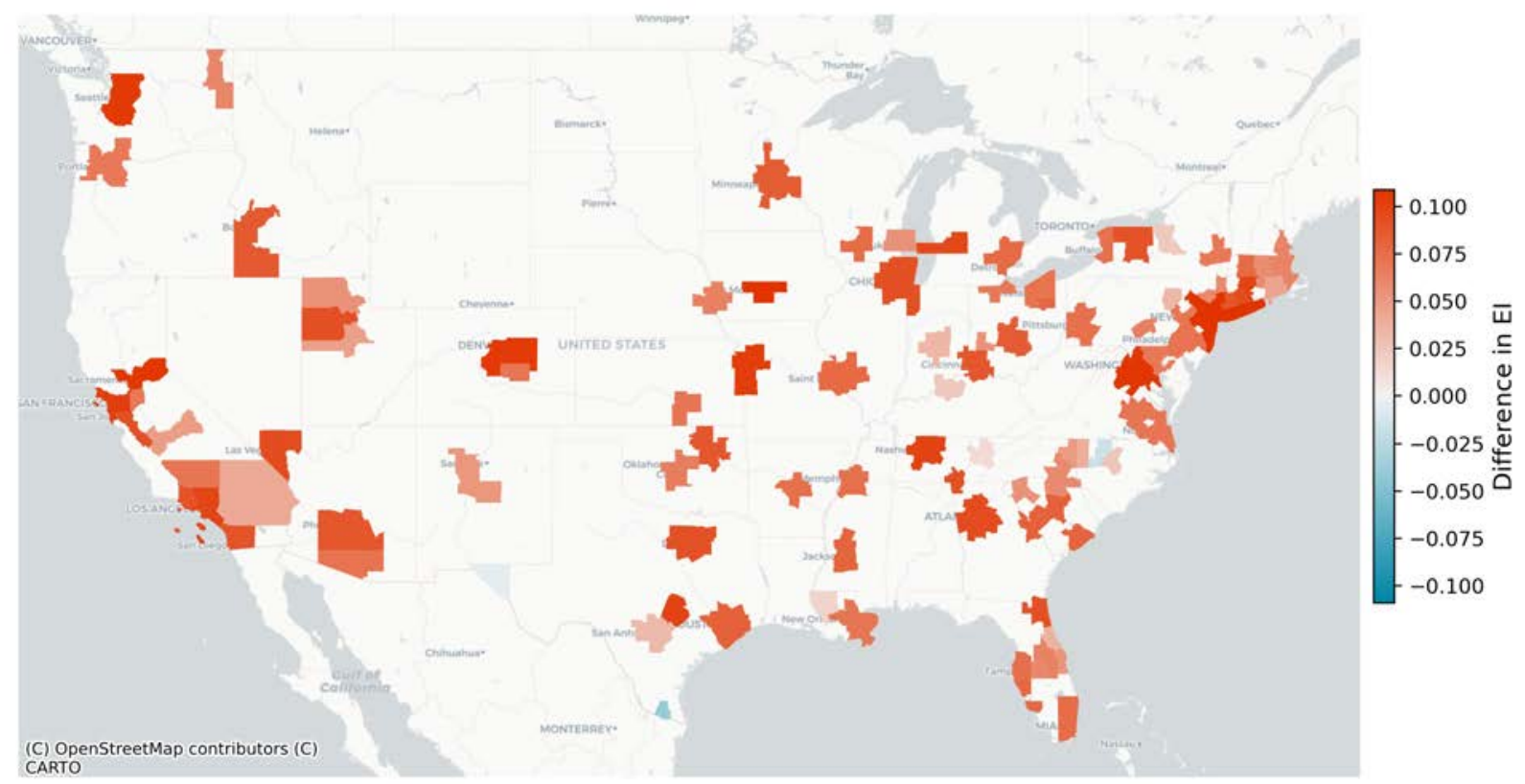

Note: These figures map aggregate experienced isolation and the difference between student and adult isolation for each of the top 100 CBSAs. 
Table B2: Experienced and residential isolation for all MSAs

\begin{tabular}{|c|c|c|c|c|}
\hline \multirow[b]{2}{*}{ CBSA } & \multicolumn{3}{|c|}{ Experienced isolation } & \multirow{2}{*}{$\begin{array}{r}\text { Residential isolation } \\
\text { Aggregate }\end{array}$} \\
\hline & Aggregate & Student & Adult & \\
\hline New York-Newark-Jersey City, NY-NJ-PA & 0.644 & 0.750 & 0.641 & 0.717 \\
\hline Los Angeles-Long Beach-Anaheim, CA & 0.648 & 0.744 & 0.646 & 0.692 \\
\hline Chicago-Naperville-Elgin, IL-IN-WI & 0.673 & 0.763 & 0.670 & 0.691 \\
\hline Dallas-Fort Worth-Arlington, TX & 0.662 & 0.750 & 0.658 & 0.600 \\
\hline Houston-The Woodlands-Sugar Land, TX & 0.664 & 0.744 & 0.662 & 0.627 \\
\hline Washington-Arlington-Alexandria, DC-VA-MD-WV & 0.650 & 0.753 & 0.647 & 0.625 \\
\hline Miami-Fort Lauderdale-Pompano Beach, FL & 0.684 & 0.758 & 0.682 & 0.673 \\
\hline Philadelphia-Camden-Wilmington, PA-NJ-DE-MD & 0.677 & 0.748 & 0.676 & 0.717 \\
\hline Atlanta-Sandy Springs-Alpharetta, GA & 0.690 & 0.780 & 0.686 & 0.655 \\
\hline Boston-Cambridge-Newton, MA-NH & 0.615 & 0.676 & 0.614 & 0.640 \\
\hline Phoenix-Mesa-Chandler, AZ & 0.683 & 0.769 & 0.681 & 0.627 \\
\hline San Francisco-Oakland-Berkeley, CA & 0.619 & 0.718 & 0.616 & 0.602 \\
\hline Riverside-San Bernardino-Ontario, CA & 0.677 & 0.718 & 0.676 & 0.535 \\
\hline Detroit-Warren-Dearborn, MI & 0.714 & 0.789 & 0.712 & 0.771 \\
\hline Seattle-Tacoma-Bellevue, WA & 0.611 & 0.713 & 0.609 & 0.469 \\
\hline Minneapolis-St. Paul-Bloomington, MN-WI & 0.623 & 0.706 & 0.620 & 0.590 \\
\hline San Diego-Chula Vista-Carlsbad, CA & 0.641 & 0.728 & 0.639 & 0.610 \\
\hline Tampa-St. Petersburg-Clearwater, FL & 0.661 & 0.733 & 0.658 & 0.588 \\
\hline Denver-Aurora-Lakewood, CO & 0.649 & 0.750 & 0.646 & 0.614 \\
\hline St. Louis, MO-IL & 0.700 & 0.775 & 0.698 & 0.725 \\
\hline Baltimore-Columbia-Towson, MD & 0.672 & 0.738 & 0.670 & 0.661 \\
\hline Charlotte-Concord-Gastonia, NC-SC & 0.667 & 0.724 & 0.665 & 0.625 \\
\hline Orlando-Kissimmee-Sanford, FL & 0.655 & 0.717 & 0.653 & 0.603 \\
\hline San Antonio-New Braunfels, TX & 0.681 & 0.711 & 0.680 & 0.533 \\
\hline Portland-Vancouver-Hillsboro, OR-WA & 0.586 & 0.653 & 0.584 & 0.438 \\
\hline Pittsburgh, PA & 0.615 & 0.687 & 0.614 & 0.604 \\
\hline Sacramento-Roseville-Folsom, CA & 0.684 & 0.788 & 0.681 & 0.594 \\
\hline Cincinnati, OH-KY-IN & 0.639 & 0.726 & 0.637 & 0.645 \\
\hline Las Vegas-Henderson-Paradise, NV & 0.640 & 0.732 & 0.638 & 0.526 \\
\hline Kansas City, MO-KS & 0.667 & 0.768 & 0.665 & 0.669 \\
\hline Austin-Round Rock-Georgetown, TX & 0.623 & 0.718 & 0.619 & 0.537 \\
\hline
\end{tabular}


Columbus, $\mathrm{OH}$

Cleveland-Elyria, $\mathrm{OH}$

Indianapolis-Carmel-Anderson, IN

San Jose-Sunnyvale-Santa Clara, CA

Nashville-Davidson-Murfreesboro-Franklin, TN

Virginia Beach-Norfolk-Newport News, VA-NC

Providence-Warwick, RI-MA

Milwaukee-Waukesha, WI

Jacksonville, FL

Oklahoma City, OK

Memphis, TN-MS-AR

Raleigh-Cary, NC

Richmond, VA

New Orleans-Metairie, LA

Louisville/Jefferson County, KY-IN

Hartford-East Hartford-Middletown, CT

Salt Lake City, UT

Buffalo-Cheektowaga, NY

Rochester, NY

Grand Rapids-Kentwood, MI

Tucson, AZ

Tulsa, OK

Urban Honolulu, HI

Fresno, CA

Bridgeport-Stamford-Norwalk, CT

Worcester, MA-CT

Omaha-Council Bluffs, NE-IA

Albuquerque, NM

Greenville-Anderson, SC

Bakersfield, CA

Albany-Schenectady-Troy, NY

New Haven-Milford, CT

McAllen-Edinburg-Mission, TX

Baton Rouge, LA

Knoxville, TN

\begin{tabular}{|c|c|c|c|}
\hline 0.655 & 0.739 & 0.653 & 0.629 \\
\hline 0.697 & 0.767 & 0.695 & 0.699 \\
\hline 0.677 & 0.711 & 0.677 & 0.647 \\
\hline 0.616 & 0.705 & 0.613 & 0.496 \\
\hline 0.640 & 0.738 & 0.637 & 0.594 \\
\hline 0.642 & 0.711 & 0.640 & 0.562 \\
\hline 0.637 & 0.677 & 0.632 & 0.656 \\
\hline 0.722 & 0.774 & 0.720 & 0.782 \\
\hline 0.661 & 0.751 & 0.659 & 0.585 \\
\hline 0.632 & 0.696 & 0.630 & 0.587 \\
\hline 0.694 & 0.767 & 0.693 & 0.694 \\
\hline 0.619 & 0.643 & 0.618 & 0.540 \\
\hline 0.672 & 0.741 & 0.670 & 0.627 \\
\hline 0.647 & 0.716 & 0.645 & 0.663 \\
\hline 0.627 & 0.650 & 0.627 & 0.654 \\
\hline 0.669 & 0.766 & 0.666 & 0.679 \\
\hline 0.606 & 0.697 & 0.605 & 0.540 \\
\hline 0.670 & 0.741 & 0.668 & 0.719 \\
\hline 0.679 & 0.768 & 0.677 & 0.745 \\
\hline 0.622 & 0.716 & 0.619 & 0.548 \\
\hline 0.684 & 0.754 & 0.682 & 0.639 \\
\hline 0.660 & 0.746 & 0.658 & 0.616 \\
\hline 0.597 & 0.687 & 0.595 & 0.663 \\
\hline 0.675 & 0.720 & 0.672 & 0.565 \\
\hline 0.631 & 0.716 & 0.628 & 0.654 \\
\hline 0.599 & 0.655 & 0.598 & 0.511 \\
\hline 0.643 & 0.705 & 0.640 & 0.605 \\
\hline 0.649 & 0.699 & 0.648 & 0.466 \\
\hline 0.618 & 0.671 & 0.617 & 0.513 \\
\hline 0.719 & 0.787 & 0.716 & 0.671 \\
\hline 0.598 & 0.665 & 0.596 & 0.631 \\
\hline 0.646 & 0.739 & 0.644 & 0.621 \\
\hline 0.633 & 0.594 & 0.634 & 0.104 \\
\hline 0.660 & 0.676 & 0.659 & 0.612 \\
\hline 0.632 & 0.644 & 0.631 & 0.589 \\
\hline
\end{tabular}


Oxnard-Thousand Oaks-Ventura, CA

El Paso, TX

Allentown-Bethlehem-Easton, PA-NJ

Columbia, SC

North Port-Sarasota-Bradenton, FL

Dayton-Kettering, $\mathrm{OH}$

Charleston-North Charleston, SC

Greensboro-High Point, NC

Stockton, CA

Cape Coral-Fort Myers, FL

Little Rock-North Little Rock-Conway, AR

Colorado Springs, CO

Boise City, ID

Akron, $\mathrm{OH}$

Springfield, MA

Lakeland-Winter Haven, FL

Des Moines-West Des Moines, IA

Poughkeepsie-Newburgh-Middletown, NY

Winston-Salem, NC

Ogden-Clearfield, UT

Madison, WI

Deltona-Daytona Beach-Ormond Beach, FL

Toledo, $\mathrm{OH}$

Wichita, KS

Durham-Chapel Hill, NC

Provo-Orem, UT

Syracuse, NY

Augusta-Richmond County, GA-SC

Jackson, MS

Palm Bay-Melbourne-Titusville, FL

Harrisburg-Carlisle, PA

Chattanooga, TN-GA

Scranton-Wilkes-Barre, PA

Spokane-Spokane Valley, WA

\begin{tabular}{|c|c|c|c|}
\hline 0.682 & 0.769 & 0.678 & 0.696 \\
\hline 0.610 & 0.605 & 0.610 & 0.447 \\
\hline 0.654 & 0.723 & 0.652 & 0.648 \\
\hline 0.688 & 0.767 & 0.684 & 0.598 \\
\hline 0.611 & 0.687 & 0.609 & 0.586 \\
\hline 0.704 & 0.756 & 0.702 & 0.748 \\
\hline 0.608 & 0.686 & 0.606 & 0.535 \\
\hline 0.679 & 0.716 & 0.677 & 0.622 \\
\hline 0.662 & 0.728 & 0.659 & 0.427 \\
\hline 0.666 & 0.742 & 0.664 & 0.529 \\
\hline 0.662 & 0.734 & 0.661 & 0.663 \\
\hline 0.635 & 0.704 & 0.633 & 0.500 \\
\hline 0.621 & 0.706 & 0.620 & 0.409 \\
\hline 0.637 & 0.715 & 0.635 & 0.571 \\
\hline 0.689 & 0.764 & 0.687 & 0.665 \\
\hline 0.630 & 0.689 & 0.629 & 0.472 \\
\hline 0.559 & 0.672 & 0.555 & 0.518 \\
\hline 0.636 & 0.693 & 0.634 & 0.575 \\
\hline 0.685 & 0.732 & 0.683 & 0.642 \\
\hline 0.558 & 0.610 & 0.556 & 0.476 \\
\hline 0.560 & 0.635 & 0.559 & 0.466 \\
\hline 0.646 & 0.681 & 0.645 & 0.526 \\
\hline 0.633 & 0.700 & 0.632 & 0.599 \\
\hline 0.622 & 0.691 & 0.620 & 0.588 \\
\hline 0.631 & 0.617 & 0.632 & 0.580 \\
\hline 0.552 & 0.598 & 0.551 & 0.413 \\
\hline 0.643 & 0.666 & 0.642 & 0.643 \\
\hline 0.674 & 0.754 & 0.671 & 0.574 \\
\hline 0.704 & 0.782 & 0.702 & 0.683 \\
\hline 0.626 & 0.678 & 0.624 & 0.436 \\
\hline 0.655 & 0.719 & 0.654 & 0.653 \\
\hline 0.610 & 0.699 & 0.608 & 0.678 \\
\hline 0.667 & 0.700 & 0.667 & 0.536 \\
\hline 0.546 & 0.604 & 0.544 & 0.503 \\
\hline
\end{tabular}

